\title{
Psychological Program
}

\author{
Duan Xian Xiang
}

\begin{abstract}
This paper attempts to reveal through case analysis that psychological activities are a set of programs and that the cause of mental illness is error in operation of the programs or the establishment of erroneous programs. By modifying or learning to use these psychological programs correctly, mental illness can be treated precisely and thoroughly. The complete psychotherapy process is represented by the following: psychoanalysis + modification of psychological programs.In order to perform certain tasks, life bodies need to initiate a series of psychological or physiological activities, which is the process of psychological or physiological activities called "psychological program". Psychological program is an abstract concept, and it is not a material entity. The search for psychological activity programs mainly depends on psychological analysis and scientific hypnosis.
\end{abstract}

Key words psychological program; hypnosis; program division; use and disuse; reference method

\section{INTRODUCTION}

In the study of clinical cases, if a large number of patients with mental illness are observed and analyzed, it can be found that psychological and Physiological activities are regular, and their combination and operation are very similar to those of computer programs. People's psychological activities can be described and analogized in the same concept as computer programs, and this psychological program can be called "psychological program".

There is also an implicit behavior in the human body that manipulates physiological activities. We can regard this kind of "implicit behavior" as "running program" and name the combination of psychological and physiological activities initiated by "implicit behavior" as "psychological program". People are different because they have different implicit behaviors, that is, they run different psychological programs physically, and people suffer from mental illness because of the disorder of "programs", psychological program disorder is implicit behavior disorder, mental illness is implicit behavior disorder, you can change a person by changing his hidden behavior.

When we pay attention to the "psychological program", we will find that the essence of mental illness and psychological disorder is this kind of "psychological program" disorder, and psychotherapy modifies this "program". It is better than changing the "belief" of cognitive therapy and the "external behavior" of behaviorism, because "belief" and "behavior" are also psychological programs, and the name "psychological program" can be used to unify "belief" and "behavior".

In the history of psychology before, many classical theories of psychology also contain the thought of psychological program. For example, Evolutionary Psychology, Intersubjectivity Theory of Psychoanalysis, Piaget's Action Schema, Eriksson's habitual 
connection Model, Executive function of Cognitive Psychology, even the Theory of body Cognition, etc. More or less, these theories have similar ideas, views, "psychological modules" in evolutionary psychology, "unique organizing principles" of inter-subject theory, and so on, which are the embryonic forms of "psychological program".

Unlike the analogy of computer information processing in cognitive psychology, this paper compares the manipulation of the body's physiology by consciousness (divided into consciousness and unconsciousness) to the manipulation of the computer itself and of its external devices (displays, keyboards, peripherals, etc.) by the computer. In comparing mental and psychological activities to the running processes of computer programs, the mode of operation of human psychological activities can also be described as a set of "programs". These programs, similar to computer programs, are abstract and non-physical and can be established and modified.

Freud's psychoanalysis is looking for psychological program, but his concrete theory is not correct, but he begins to look for psychological procedure. Throughout the psychotherapy process, Freud's psychoanalysis is the first part of psychotherapy: psychoanalysis. However, it is far from enough to find the psychological program only. In order to treat mental and psychological illness, we still need to modify the wrong psychological program.

This paper begins to present the pattern of the psychological program in the form of case, and then explains the definition and connotation of the psychological program. The paper, through the combination of people's psychological activities, is regarded as psychological program, it is considered that the personality or the sexual behavior, whether the temperament or the mood, can be regarded as the psychological program. These programs will trigger the corresponding physiological response, and the program is wrong or the operation is not at the time, it is easy to cause the physiological reaction disorder, these physiological reaction disorder can bring the real physiological pain to the person, and in order to alleviate these pain, the patient will make some crazy behavior, The patient looks like a "a madman".

When using the concept of "psychological program" or "mental program", we can find that psychological program exists in all living things, whether it is human beings, apes, monkeys, chickens, ducks, snakes, turtles, beetles, trees, flowers and plants. Even the motion of inanimate objects can be regarded as "programs", and the motion of celestial bodies and chemical reactions can be regarded as "programs". The gravitation equation is the description of the movement program of celestial bodies, and the laws of thermodynamics are also the description program. The physical laws and laws are the "psychological programs" of inorganic substances. The difference between the program of inorganic matter in nature and those of living things like humans is that the programs of the universe, such as the laws of physics, do not seem to change, even when magnified to the scale of billions of years, or they change very slowly, even on the scale of billions of years, we cannot see them. However, the program of an organism like a human being can be changed, and the organism itself can consciously or unconsciously control its physiological activities to change or establish its psychological program.

Although the movement of human beings, human society and the inorganic material world can be described by "procedures", human psychological procedures are similar to the laws of physics. But, the human body's psychological program can change, the human society's movement rule uses "the program" this word is more accurate than "the law". 
In terms of research methods, before Wilhelm Wundt, philosophical speculation was used, and after Wilhelm Wundt and Wilhelm Wundt, introspection and experiment were used. Today's psychologists think that Wilhelm Wundt used the "experimental method", but, in fact, he meant it to be "introspective". However, he believes that traditional introspection is flawed, introspection needs to be done in the laboratory and trained. But such "introspection" is wrong, and there is no need to add "experiment" to introspection.

This paper argues that psychology is not fit for experimentation or statistics. It is not that experimental method cannot be used at all, but because of legal and ethical limitations, it is not appropriate to use experimental method and experimental method cannot be used as the main research method. Statistics is the study of the psychological characteristics of groups, not individuals. Statistics deals with groups rather than individuals, but for psychology, it's really about individuals, and the probabilistic conclusions of groups don't apply to individuals. Moreover, the behavior of individuals suitable for statistics is random, but the behavior of people is not random. So there's no point in using statistics to study psychology. Psychological research methods need to change.

In physics, the first research methods were "analyse mentally" and "observation". Later, when Galileo came, there were experiments, and then there were mathematical deduction. One can compare the methods of psychology and physics, and it is clear that psychology is not yet at the stage of mathematical deduction.

Psychology and physics, from the perspective of researchers, one is the internal spiritual world, the other is the external nature. The existence of psychology and physics has the "opposite" tendency, one is inside, the other is outside, so the observation direction is of course "opposite". That is, psychological observation should be inward observation, inward observation is "introspection", physics is outward observation, astronomical observation is outward observation.

Introspection is the observation of one's own mental activities, including "researcher introspection" and "subject introspection". "Researchers introspection" refers to the psychological activity, psychologists observe their when psychologists encounter an event, such as "anxiety", based on his own psychological analysis, looking for the reasons of anxiety, recall events cause anxiety, so, cause "anxiety" of psychological activity will appear, this is the introspection, introspection is not observe their Wilhelm Wundt said the current psychological activity psychological activity, but his former psychological activities including mining, memories and psychological activity in the introspection himself about something.

"Subject introspection" includes patient confiding, psychological tests, questionnaires, etc. All of these have to go through the patient's introspection, so they are all introspection.

In the history of psychology, Freud, Carl Gustav Jung, Adler, Maslow and others used introspection. Freud established a system of psychoanalysis through his own introspection and the introspection of patients. Maslow studied biographies of celebrities and was "the introspection of subjects".

In fact, the best analogy is between psychology and astronomy, neither of which is suitable for experiments, but both are suitable for instrumental observation. In astronomy, observations can be made with many instruments, such as telescopes. In psychology, there should be instruments for observing psychological phenomena, and fMRI is. In the future, special instruments would have to be invented to observe psychological phenomena, just as 
Galileo had invented the telescope. The mental phenomenon seems to take place in the whole body, so the physiological observation of the mental phenomenon should be in the whole body, not just in the brain. We cannot bring the universe into the laboratory to observe it, nor are we fit to bring man into the laboratory to observe it. Micro-instruments can be installed on the body of the subject of study, without affecting his work and life, to observe his psychological phenomenon in the society.

Although psychology is not suitable for laboratory experiments, there is one kind of research approach that is close to the experimental method, and that is the "clinical treatment", including the clinical treatment in psychological clinics and psychiatric hospitals.

For the above reasons, the research method of this paper is not an experiment. In fact, it's hard to observe psychological programs in the lab.

\section{NEUROLOGICAL PSYCHOLOGICAL PROGRAM}

\subsection{PSYCHOLOGICAL PROGRAM DEMONSTRATION}

This case is from China's baidu tieba. The case is true, and it was the client's "psychological consultation bar" that made the public consultation, but it was anonymous.

A first disclaimer here is that the psychological program analyzed in the following cases is accompanied by no guarantee of its accuracy or comprehensiveness in regard to the specific psychological phenomenon described in each case. For example, in the anger program in Fig. 3 , the psychological program in the box does not include all the psychological programs related to anger and may not necessarily be accurate. These block diagrams are only examples of "psychological programs."

The following is a case of obsessive-compulsive disorder (A);

Counselor: what's bothering you?

Client: my liver paining. The pain in the right ribs of the body, my back make me uncomfortable.

Counselor: did you go to the hospital for an examination?

Client:check! check out disease, fMRI, CT, X light, all as before, the doctor said wasn't sick, but I know my illness is very heavy, I may have cancer of the liver, and other disease.

Consultant: If liver cancer reaches the level of pain, it can be detected.

Client: many cancers can't be detected in the early stages. The doctors are not good enough. My liver hurts.

Consultant: why liver pain? Since when?

Client: long ago. It is serious these years. I am going to die! 
Counselor: when the liver paining, what's the matter? It was caused by something?

Client: angry! When I was angry, I felt the pain in my liver, the pain in my right side, the pain in my back, the pain in my chest.

Counselor: when you're angry? Very angry? How did you get angry? Can you describe how angry you are?

Client: When I'm not happy, I get angry.

Counselor: so angry? Are specific because of what matter angry? Did your liver pain when you were a kid? From when angry liver can ache?

Client: I've been angry for years.

Counselor: what made you angry at that time? How did you get angry at that time?

Client: oh, I remember. It may have something to do with a childhood event.

Consultant: tell me more about it.

Client: When I was 13 years old, I didn't go to school because I was bad at mathematics. I stayed with my mother at home. At that time, my mother had a bad temper, and she was easily angered, partially because my grandmother often made life difficult for her. I helped her with housework. She always said that I was stupid and dumb and swore at me sometimes when she was frustrated. I was depressed every day, unhappy, but of course, I wouldn't really be angry at the time.

Counselor: not really angry?

Client: yes, mother is very tired, very bitter, and very fierce. I dare not be angry with her!

Client: Once, I did not manage to light the fire for cooking. She hit me and asked me to drown myself in the river. I strolled around the river and didn't dare to jump in. I went to the neighbor's house instead. My mom later called out to me in the streets. I came out, and she told me that she thought I had jumped in the river and had drowned, so she came to get me.

Client: One day, I watched TV after dinner. I sat in the innermost position. On TV, there was an advertisement for medicine, in which a mother asked a father if frequent anger would cause liver or stomach disease, and the father said yes. It went to my heart. Since then, I have also learned to be angry. I was angry even when I was sleeping.

Counselor: until then, don't you dare get angry? Not angry?

Client: no, just not. And then, after that, 
Client: I was angry during the day too, and felt inferior and in a daze every day. My mother said that she might as well have strangled me when I was a baby, seeing me this way. I couldn't get this out of my heart. Until now, whenever I suddenly remembered this, it would make me uncontrollably angry.

Client: She often scolded me, and so I was often angry in silence, including when sleeping, because I did not know how to refute her words, I was quite tame, and slowly it became a habit. Especially when I slept, I couldn't sleep well, and it lasted for a year.

Counselor: stop. She said why don't you strangle yourself? You can't get out?

Client: yes, from then on, when she started yelling at me, I was silently angry.

Client: I have worked far from home since I was ten years old. I was a loner away from home too. Later, at the age of sixteen, I raised chickens in a chicken farm and was also bullied. Later in the factory, a team leader felt that my salary was similar to hers, and she was jealous. She yelled at me and gave me tough work every time. She even laughed at me with other team members. I still did not know how to fight back. Working there for a year filled me with anger too. At that time, in 2011, I had pain in my body, around the right side of the ribs. Later, I felt pain every year. I started to suffer badly starting last year. I discovered that I was dying.

Counselor: is your silent anger taking a bit of a fight back to protect yourself?

Visitor: ah, you are right. It means to fight back and resist.

Client: You are right, it was self-protection. I thought my anger would stop anyone from bullying me, and I didn't need to resist any more, but no. My body on the right side was harder than the left on the whole.

Counselor: what do you think is the benefit of getting angry like that?

Client: It is a way to vent. I feel that I have learned to be angry to have a way of venting. I felt that I had found an exit, as the reality was too oppressive.

Counselor: you use anger to vent, to relieve the sadness and anger in your heart? Anger gives you an outlet for your stress?

Client: That's it. Who knows, I can't go back anymore.

Client: I am in too much pain to work. I am in pain every day; I can't sleep for whole nights; I want to cry, but there are no tears, and it hurts.

Client: When I deal with strangers, some of whom may not be very nice to me, I will be in pain, but for the sake of harmony, I do not say anything, but I sulk. Now it has come to the point that I am angry when nothing at all happens. I have no way out of it.

Client: My body is sick because of the anger. I get so angry every day. My liver will become 
cancerous like this, but I can't stop it.

Client: It has affected my health; I can't sleep at night, it affects my body, and I can't go to work. I used to think that I could bear it, but now I am very afraid because I don't just feel uncomfortable in the right rib - now my chest and heart and the entire chest have a burning pain.

Client: I also imagine that if I am sick someday, where will I go? Will I be afraid of the cold, have a very sad life? When it is cold and when it rains, where will I be placed? Will I feel lonely?

Counselor: first of all, you suppressed your normal impulse to get angry in childhood. Later, then, you only dare to be angry in silence, with anger to passively fight back and vent sadness. Your abnormal anger habit forms a pattern.

Client: it should be so. It forms a pattern.

Client: what should I do then? I don't have liver disease?

Consultant: no. It's your anger pattern that affects your physiology.

Client: what should I do then?

Counselor: it takes time. First of all, I will analyze with you the angry habit you had in your childhood, how it happened, how it happened to you, and why you dare not be angry with your mother. There's a lot to analyze. You need to be aware of the process of your anger, how it started, the physiological sensations it has in you. This is important because only when you are clearly aware of it can you control it and give it up later.

\section{Client: Perceive? How?}

Client: Yesterday, I noticed that my right body was tight, my arms tense, in a state of tension. When I am angry, my esophagus experiences discomfort, too. If I continue in this way, I will have all soClient: Yes, very serious these days, that is, when I wake up, in the first few seconds, I would start to perceive, analyze, struggle with whether to go on like this, and start suffering. Then, the right side of my body gets tight, and there is a sense of oppression, followed by anger. It feels like my back tightens, too, like a knife stuck in the back. Very painful. I also told myself in my heart that no one is bullying me now and that there is no need to resist, but it is useless; I cannot stop it.

Client: First of all, the thoughts flashed through my mind, and then, the body began to tighten, especially the back, waist, arms too. Breathing gets difficult, anger burns like fire.

rts of illnesses and die a painful and terrible death.

Client: Morita therapy? Can it help my problem?

In the above case, the patient's psychological program can be analyzed as follows (see Fig. 1) 

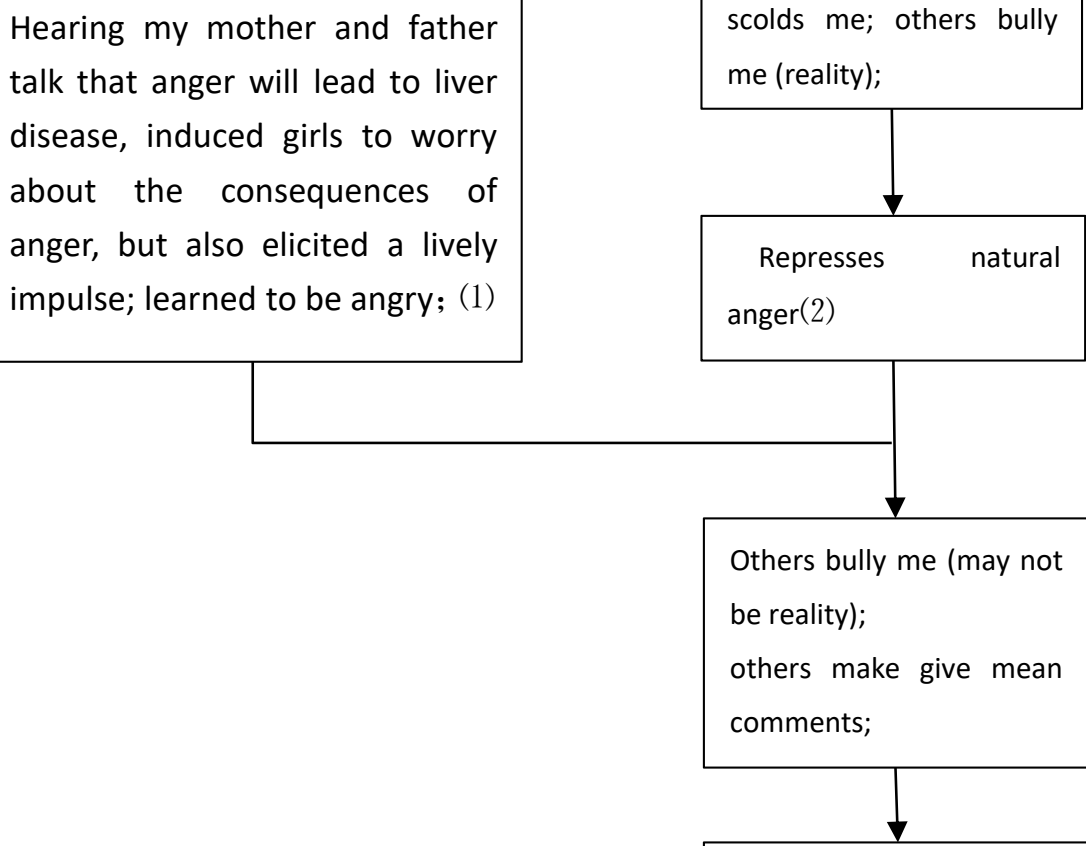

Forced anger to resist (inward anger)

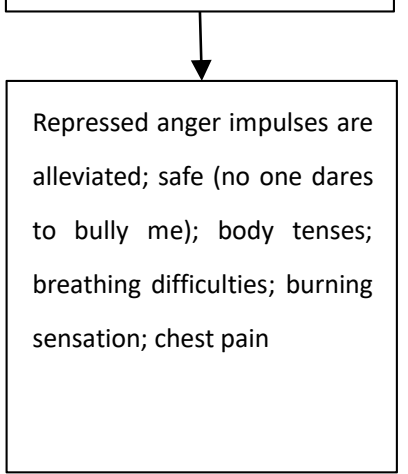

Fig. 1

Figure 1 shows the patient's morbid anger program, which is because she was always beaten and scolded by her mother in childhood but suppressed her anger. Later, when she heard her father and mother discuss whether anger would cause liver disease, she induced the urge to get angry, thus establishing this forced anger.

Figure 2 below shows the normal person's anger program, which is a healthy anger program, and we can compare the two programs. When "my mother hits me, scolds me", the healthy person will start the program (10, that is, "start angry reaction", but the girl in the case 
will "not get angry", that is, she uses the program (2), but she is actually angry and impulsive, but her mother is too strong to be angry, so she does not dare to be angry until "Mom and Dad discuss that anger will cause liver disease", that is, program (1), her anger impulse is induced. From then on, she established figure 1, a program of forced anger, and used forced anger to protect herself and relieve stress and anger, and so on.

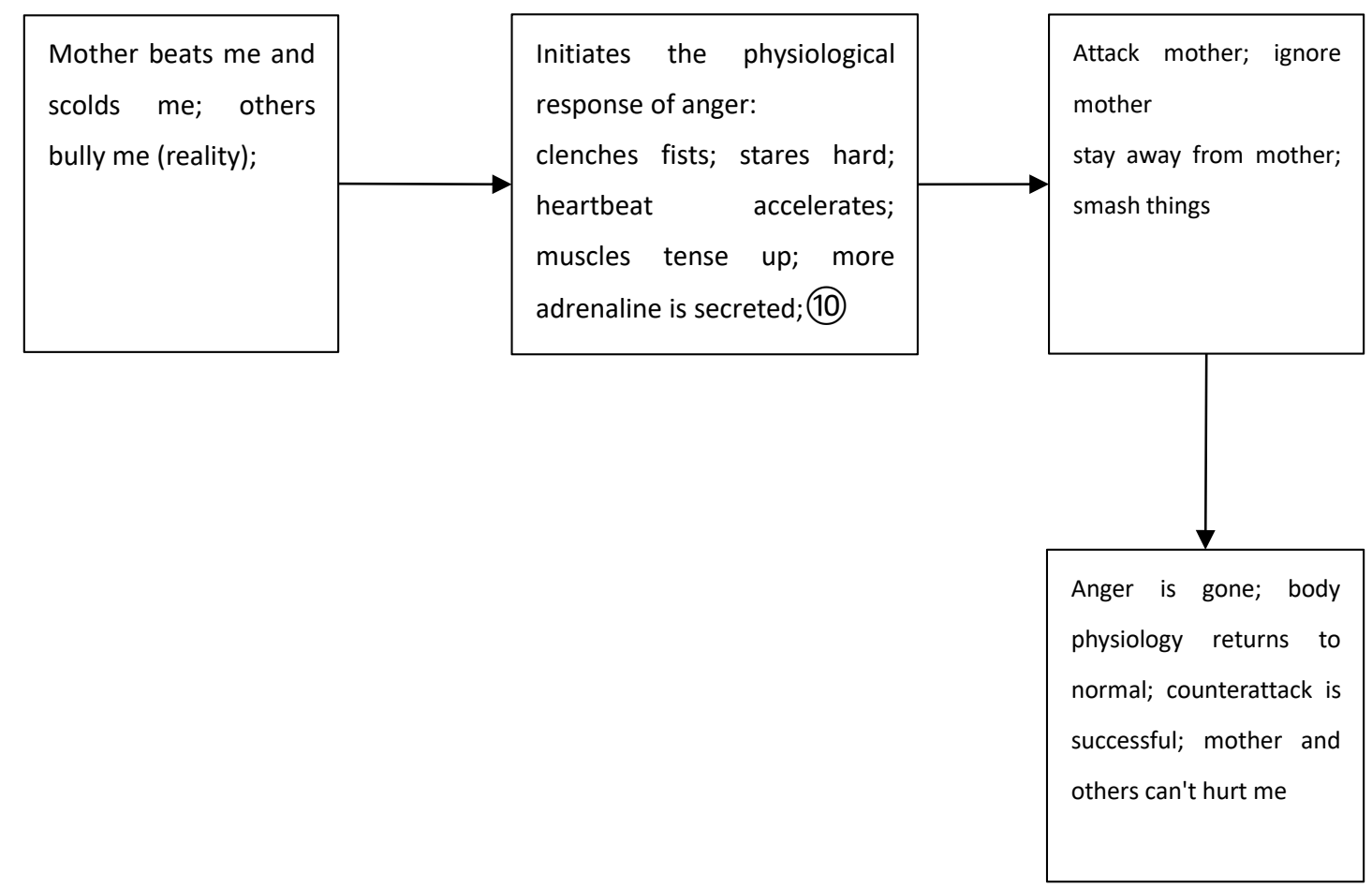

Fig. 2

The sentence in each box (separated by ";") describes a program. The patient initiated the psychological program, and the arrows indicate the order in which the psychological program is run. If the program described in each sentence is used as the parent program, there are subprograms under the parent program and still lower level programs under the subprograms, which are linked by certain rules. Figure 3 below shows the angry program, Fig. 4 shows that there are some subprograms under the "rapid breathing" program. The above patient's pathological anger program is also part of a larger program, i.e., her program of interacting with her mother (Fig. 5).

As can be seen in Fig. 4, a "rapid breathing" program consists of a series of physiological activities: the respiratory center sends out nerve impulses, the diaphragm moves up and down, the alveoli expand, etc. These physiological activities can be subdivided into more granular physiological activities. These physiological activities can be considered as part of the psychological program. 


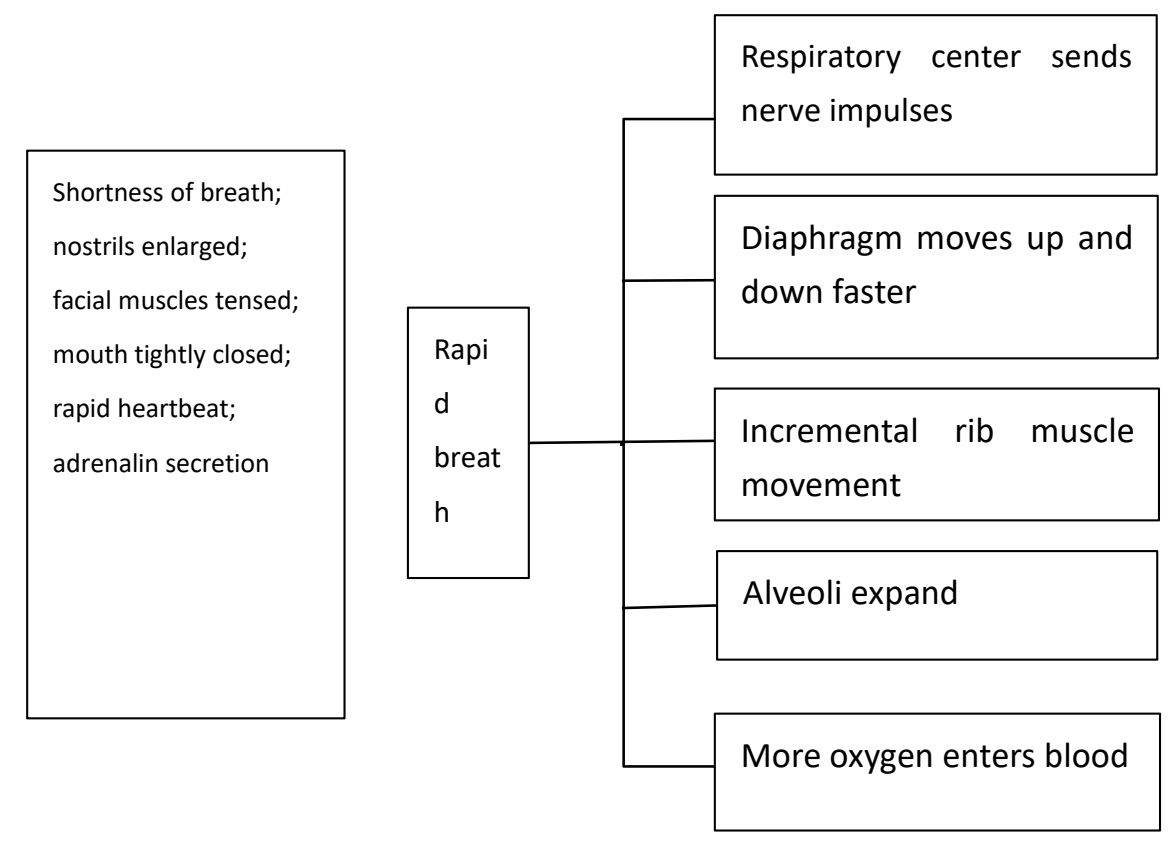

Fig. 3

Fig. 4

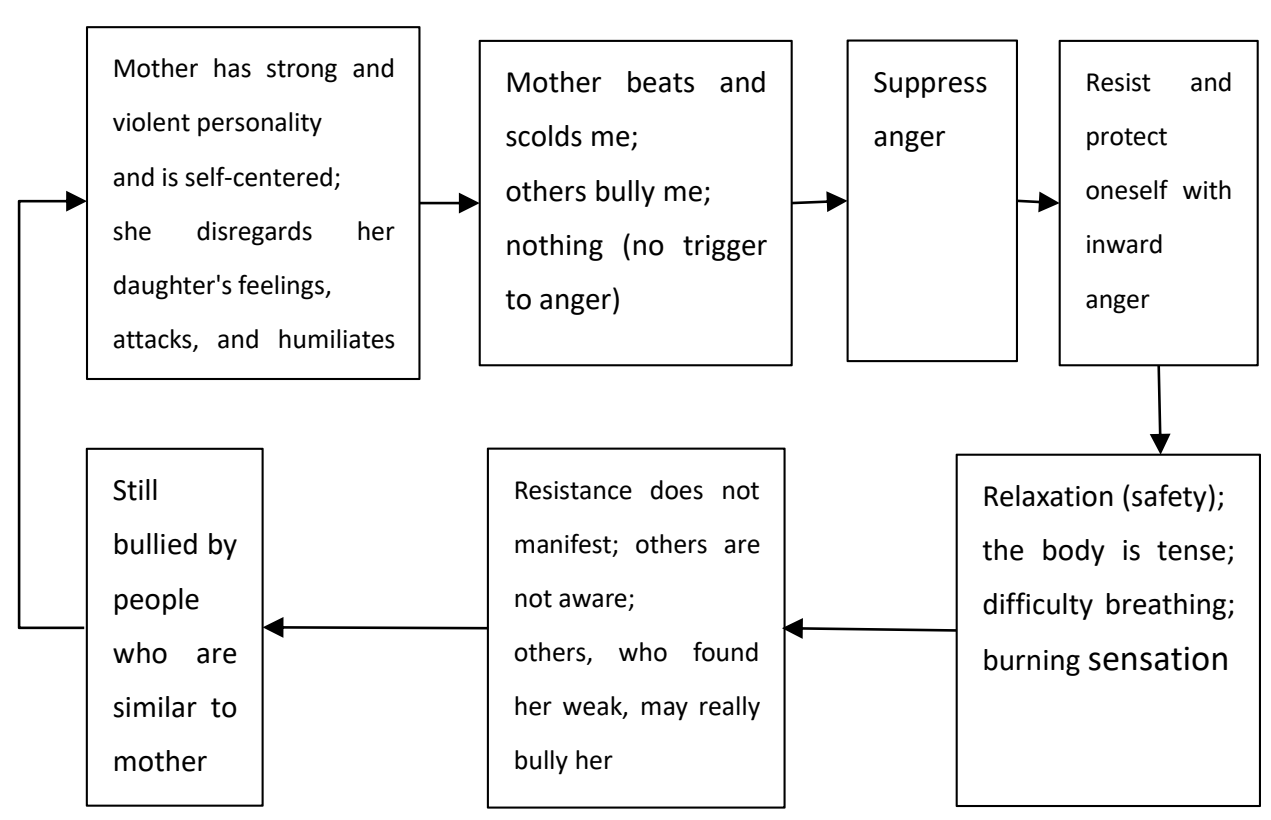

Fig. 5

In the above flowchart, you can see many physiological activities: mother beats me, heart rate accelerates, and smash things. These physiological activities are combined with each other in a certain order, time of occurrence, intensity of occurrence, etc. to form the psychological program shown in the flowchart. This combination is abstract, and it shows that 
mental activities have patterns. It runs in the same way as a computer program. This is the psychological proConsciousness can influence and control physiology. The psychological program is an organic combination of a series of processes that control and influence physiology. The psychological program acts on physiology via consciousness. In Fig. 1, in the program "mother beats me, mother scolds me," the "mother beats" part requires the mother's consciousness to carry out a series of physiological activities and initiate corresponding physiological reactions. Her brain must give orders to the body, i.e., "brain giving commands to the body (the arm)" is physiologically reactive: the nerve center sends nerve impulses, etc.; her hand is lifted up, and this "lifting hand up" movement also represents a change in her physical physiology. Program.

That is, in Fig. 1, the client's psychological program is realized through a series of physiological changes, from "mother beats me, mother scolds me" through "repressing natural anger" to "body tensing up, breathing difficulties." These physiological activities require the participation of the client's consciousness, and her consciousness (including unconsciousness) guides and executes these physiological reactions (although many physiological reactions are not what she wanted, they occurred because her body was running the erroneous programs, so she produced these physiological reactions) in order to achieve the purpose of "venting anger, symbolically fighting back against bullying."

\subsection{Reasons BEHIND HER establishING and usING abnormal psychological programs}

Of the programs shown in Fig. 1, the most important ones are "repression of natural anger" and "forced anger to resist." The client consciously suppressed her angry impulse here, controlled "anger" with "consciousness," and established a new, abnormal psychological program, thereby originating her psychological disorder. The establishment of this program was achieved by controlling her physical and physiological activities, which indicates that the establishment and change of psychological programs require subjective consciousness to be applied to the body's physiology.

In front of others, she suppressed her anger and did not let herself lose her temper. However, she was secretly "angry" when she was alone. This approach could accomplish the avoidance of conflicts with others while still allowing anger to be used as an outlet and "resistance." However, she did not know that this was erroneous and dangerous.

The normal anger program is caused by the inducing condition: "mother beats and bullies me," and naturally, the client would start the normal "anger program" against her mother. However, the problem is that her mother was different from other mothers, and her resistance might bring more terrible consequences. Her living environment was special too- she was only thirteen years old and could not leave her mother and survive. Therefore, she could only choose to distort her anger program to adapt to the environment.

Therefore, she did not initiate the natural angry reaction program at the time (Fig. 2) but suppressed her experiences instead. Later, she consciously angered herself inwardly (i.e., in her own mind, not outwardly expressing it) using her own obsessive-compulsive disorder 
program (Fig. 1). Because this kind of anger could alleviate her anger, sadness, and other emotions, the client felt that she had found an emotional outlet.

The compulsive anger program in this case is significantly different from the normal anger program. Normal outward venting can break the vicious circle of being bullied, but when she engaged in such venting, the client was still bullied. This program was not only useless to her but also harmful.

Her problem was not only her erroneous anger program but also her socialization program. When she was bullied by others, she would have been better served by fighting back and not being angry on the inside. She needed to be angry with the bullies and fight back. For her, the larger program, the socialization program (Fig. 5), became erroneous.

\subsection{HOW TO TREAT IT}

The psychological treatment of this client should begin with telling her that she should fight back against others' bullying to protect herself, that the external environment has changed (i.e., that she is not with her mother anymore), that the people she now encounters are differ from her mother, and that she is not the little girl of yesteryears but instead is capable of make a living independently now.

Even if she meets characters like her mother, she can choose not to interact with them, thus actively changing her external environment. That is, she must first change her abnormal programs (Fig. 1), and through socialization, she needs to actively seek healthy interpersonal relationships - that is, not become close with people like her mother (who are, in fact, rare). This will require that she change her socialization program. Only in this way can her problems be truly cured.

In this case, the therapist's job is to help her abandon the erroneous obsessive-compulsive anger program (Fig. 1) and switch to the appropriate anger program (Fig. 2).

Because psychological programs are composed of a series of physiological activities and because these activities are manipulated and influenced by consciousness, the client in this case can intentionally establish the erroneous program of Fig. 1, and she can also give up the erroneous program. Using the "use and disuse" method mentioned later under the modification methods of psychological programming, she can give up the previous program and re-learn use of the program in Fig. 2 according to the principle of "the previous program is stronger."

From this case, it can be seen that the patient can use her will to suppress the operation of the normal psychological program, and she can also intentionally establish the program of Fig. 1. All of these actions are the result of her control of her own physiological activities (e.g., repressing the anger impulse, intentionally getting angry by herself). This indicates that the psychological program can be changed.

Regardless of how diverse and complicated these erroneous and correct programs are, in 
many cases, even the patients themselves instinctively know what is appropriate and what is erroneous, such as the client above, who knows that getting angry that way was not the right way.

Blair, a friend of Freud, found that once a psychiatric patient was hypnotized, his symptoms were alleviated because he recalled the programs under hypnosis and instinctively and quickly modified them or because he realized where the errors arose and knew what to do about it, thereby alleviating the anxiety. Because of the speed of this modification and awareness, neither the patient nor Freud noticed the process and mistakenly believed it to be an effect of free association of psychoanalysis or the role of hypnosis itself.

Most of the time, patients don't know what psychological programs are right, what's wrong, and it's hard to recall how they happened and how they worked, and the hypnotic technique is very important and valuable. The separation and modification of psychological program is inseparable from hypnosis.

\subsection{PSYCHOTHERAPY IS TO CHANGE IMPLICIT BEHAVIOR.}

in a case, we can regard the operation of psychological programs such as "suppressing natural anger" and "forcing anger to resist" as implicit behavior. Psychological disorders are due to the fact that these implicit actions are deranged. To change the psychological program of figure 1 into the psychological program of figure 2 is to change the implicit behavior of the patient.

\subsection{PSYCHOANALYSIS.}

Therapists receive patients, the first important task is to collect information, one of the most important is: ask. For example, in this case, the therapist first asks the patient about her symptoms, she confides in the pain in her right flank, and so on. Then, the therapist asks her what caused the "pain," and the patient will say "angry," and then, Ask again why "angry" patients talk about childhood experiences.

When the patient talks about her history of anger, the therapist needs to understand her anger process accurately, meticulously and thoroughly. In serious cases, patients can not recall the pathological "psychological and physiological activities", so hypnosis is needed to guide the patients to speak out. Excavating these "psychological and physiological activities" is not just for the therapist, but more importantly, for the patient to be aware of these "psychological and physiological activities" so that she can modify it.

Like a detective, the therapist needs to follow various clues, find out the specific psychological process of the patient, and "show" the psychological process of the patient by the same means as a "microscope".

Collecting information can be done by asking the patient directly about her psychological activities or indirectly, such as a patient's diary, family relationship, psychological test, housekeeper, sand table, etc. In short, the process of understanding her psychological activities by various means.

\section{THE PSYCHOLOGICAL PROGRAM OF DEPRESSION}


Patient: at first is too small, also does not quite understand, cries ah. I lived with my grandparents in kindergarten. Primary school goes to my mother. I really want to go back to my grandparents. Then my mother would force me to call and criticize my grandparents for being old. Why not die? But at the end of her own regret, hugging me, crying, coaxing me, I was a little confused, and then I began to hate her.

Doctor:hate, hate mom at first?

Patient: yes. Hou was too young at that time, there was no depression in primary school, I was very cheerful personality at that time. When class leader, captain, but also when the city's top ten teenagers. Perhaps at that time, my psychology was too strong. My mother was with her later husband.

Patient: every day fighting, falling bowls, I also go to clean up the pieces

Patient: once in a fight, the man in front of me broke two of my mother's tendons with a knife. My mother was hospitalized and went home with plaster and they were fighting. My mother is always in a mess of clothes, yelling, drinking toilet water, picking up trash pail paper to eat.

Patient: she was sick then, too. She hit me, jerked me all over, dislocated my fingers, hit me on the head with a stool, and bled. Then I cry, she won't let me cry, I cry she will put soap in my mouth. I was so tolerant, I didn't go crazy.

Patient: very good to junior high school, especially good grades, or captain, but a little bad omen. That is, self-harm, a bit of brain damage, not the mainstream kind of, gradually the character becomes irritable.

Patient: at that time, my mother divorced the man again and was dating another man. We are in a cold war with each other. She's looking for her boyfriend. I'm playing my non-mainstream.

Patient: then, my grades dropped, the teacher looks for the parents. My mother wanted my father to come, but my father wouldn't come.

Patient: when I was in high school, I developed physiologically. Often sweating, dizziness, headache, insomnia, nausea and vomiting, then sleep, it is 12:00 every day, but four or five o'clock wake up. Then, I quit school, took medicine to see a doctor, and kept it at home.

Patient: doing nothing every day. My family said I pretended to be sick.

Doctor: why suddenly? Aren't you mentally strong?

Patient: it seems that the material aspect has been able to meet the needs, but the spiritual aspect can not be pursued? If you are rich in your family, you can buy anything you want. But, always thinking, alas, in my life, I have never had a good day of a family of three, and this 
kind of day, I will never get it again, no matter how hard I try.

Patient: angry, resentful God. I also feel bad luck. And I feel sorry for myself.

Patient: it's material satisfaction, and you start to pursue something else. And find that this pursuit will never be achieved.

Patient: but it doesn't seem to be my fault. Bad grades, too, because of this.

Patient: that's the kind of family of three. For example, when I go to play at my classmates' house, I will see their parents cook daily and make fun of each other's dishes. I will envy, will especially want to feel. Went to my father's house, he later reorganized the family, gave birth to younger brother, saw their family life. And you think, he's my dad, too. why?

Patient: Every time I go there, my father is cooking and washing the dishes. The woman sometimes joked with he, like a child. I would like to feel like a family of three, and I think my mom and dad hold my picture. It's still in the fantasy.

Patient: my family is a third party intervention, my father is in the army, my mother is a soldier's wife, she can't see my father several times a year. When she was pregnant, my father had never seen her pregnant. When I was very young, my mother took me to see my father. It's a long way to go, so it's not easy for my mother to have a deep grudge against my father.

Patient: then, I was more than two years old and they divorced. My mother went out of town by herself. In fact, they are very suitable, my mother is very lively, cheerful, childlike woman, my father is the kind of more introverted, silent, occasionally cold humor people.

Patient: I think I would be happy if they were together. It will be better than it is now. In fact, I killed myself early this year, and then I did a MECT, in the hospital. My father came to take care of me, but he was very polite when he talked to my mother. He didn't feel like a family at all.

Patient: boring life.

Doctor: what you want most is a happy family?

Patient: yeah, but it's an impossible dream. My doctor told me to look forward. The problem is that I have nothing before me.

Patient: my mother told me that you can have a happy family after you get married. But you know, not what I want. The only thing one cannot choose from is birth. The happiness of being a wife is different from being a daughter.

Doctor: you lost that daughter's happiness, and then you desperately wanted it and didn't get it. 
Patient: yes. Even father loves, mother also loves, for example, see other people mother scolds daughter, father will protect, or mother does not give allowance, but father will give, that kind has father.

Patient: let's say my father died before I was born. So where do I find my father's love in the rest of my life? Then, the rest of the existing everything, can not let me have the feeling of "want". I feel, meaningless, unhappy. In a word, even if I became the number one in the world, I had no fatherly love in my life.

The case was accompanied by Baker's depression model, the learned helplessness model. The girl wants the warmth of her family and the love of her parents. However, she can't get it, but she must, because it is the instinct of life, and for women, love is the most important thing in life. However, the family environment of the girl's childhood did not allow her to meet such needs. The more she did not get it, the more she cared, the helplessness and despair she received surrounded her, and she "learned" and "helpless." Of course, just "helpless", "powerless" is not going to be depressed, but if it's so important that you have to get it and you can't get it, depression can happen.

The girl's problem was that the family was unhappy when she was a child and a young girl, and she wanted the happiness and warmth of the family and wanted a warm life for a family of three, but she didn't get it. When she grew up, she longed for the "happy family life" that had been lost, even though she knew that it had been lost, and that time would not go back, and she would never have the chance to experience it, but she would like to experience the well-being of the family that had not been felt, and that was almost an obsessive-compulsive disorder. So, she's in a depression.

The girl's psychology is similar to that of PTSD,. When she was a child, she wanted her family to be warm and could not get it, but she was not in the mood to pay attention to it (because survival was more important). Later, she got better, lost the warmth of her family, and the trauma of no fatherly love and maternal love poured in. She remembered that she had never experienced "the happy life of a family of three" and that the experience of "family warmth" had been "lost."Her life lacks this kind of experience, she wants this kind of experience, but, this is impossible, because time will not turn back, therefore, the childhood lost "family happiness and warm father love mother love." Without a chance to experience it again, she couldn't do it, so she was depressed.

In general, a person loses his favorite article, can be sad for a while, and finally can be recovered, but the loss of the girl in the case is too important for her, so she can't stand the "lose". It's lost. It's just to lose. It's just like we've lost all the other things we love.

The pursuit of what you can't get, but you feel that what you can't get is very important, you have to get it, but you don't get it in fact, so people's psychology is stuck here, which is the cause of depression. Your attention can not be diverted, can not focus on and do other things, your heart always remember this "it", can not be interested in other things; At the same time, your body will never forget the despair and depression, and you will be in a bad mood. In fact, this is the psychological program stuck here, like a computer crash.The solution: either try your best to get this thing or just give it up.

When you get it, you don't get depressed. When you know you can't get it and give it up, 
you don't get depressed, but you don't get stuck here. But depression can occur when you don't get it and feel it is important to you to not give up.

In this case, the girl's depression is not because she can't get the happiness of her family ("not getting" itself does not cause depression), but because she can't get the happiness of the family, but she wants it very much. Therefore, the therapist must first change the girl's cognition and tell her that she did not experience that kind of family happiness, which is true. Since she has not experienced it, he can only endure this lack and accept the incompleteness of life.She had to give up something she could not pursue, though it would make her feel a psychological lack of a piece, but she had to put up with the "lack of". She needs to make a choice: to give up the lost "The family is warm, the father's love", or to depression.

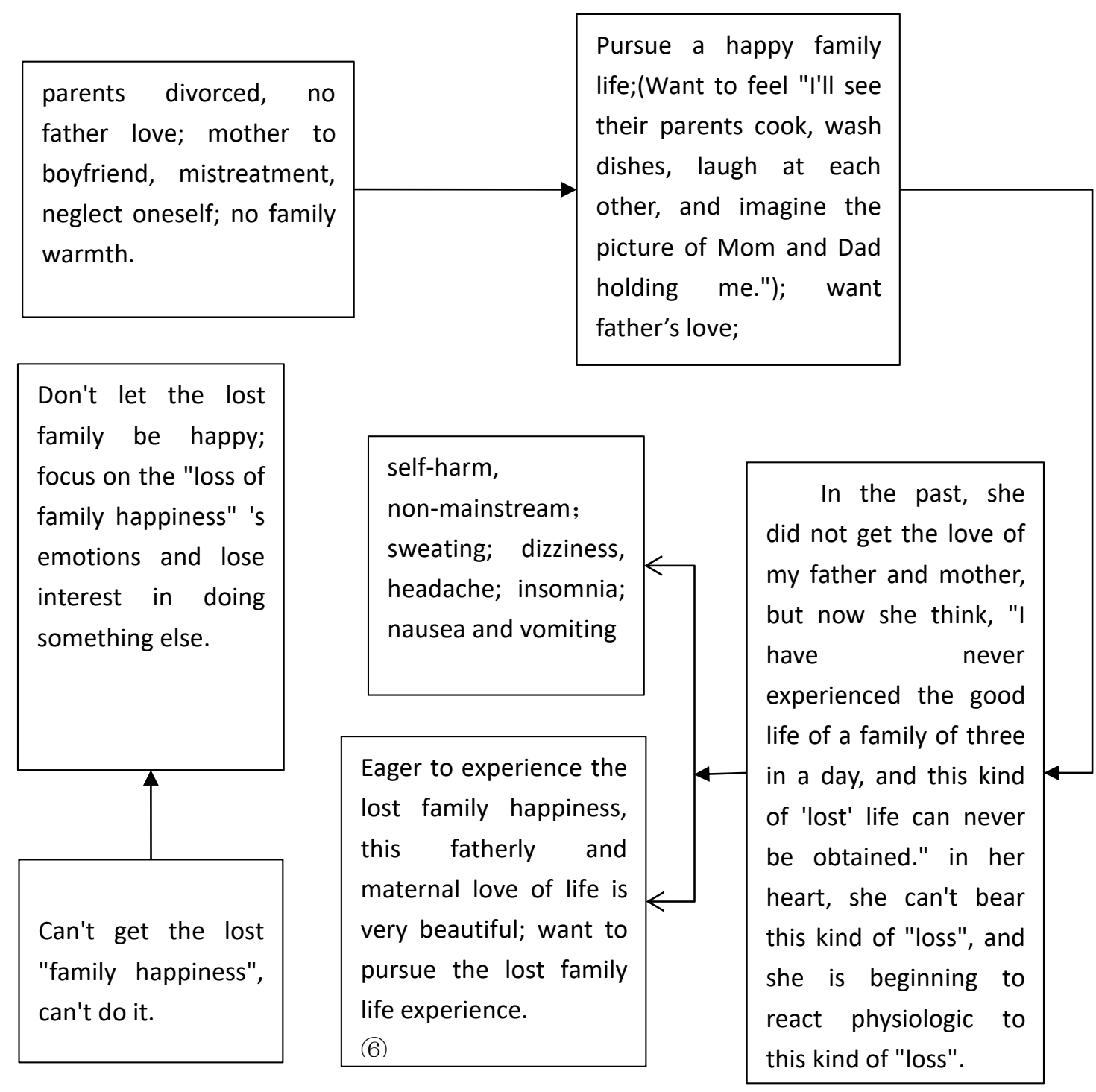

Fig. 10

Psychiatric treatment is to modify the psychological program or change the way the program works, and girls need to modify the psychological program in figure 10. Starting 
with program (6), she has to change the direction of the program and stop running the later program (which needs to be done slowly). She must stop her forced desire for the loss of "family happiness" and "fatherly love", accept the fact that she did not get it, accept the fact that she did not experience it, and accept the incompleteness of life.

From here on (6), she is changing the process of psychological activity, and when she can control and change the process of her psychological activity, stop pursuing the "family warmth and happy" and "father's love".

In the block diagram above, the mental program seems to be an abstract, nothingness description. For example, the description of "want a good day" really seems too empty, not like an empirical behavior. But it's a program of physiological response, and when she wants a "good day," her body has a corresponding physiological change, her body's chemical transmitters, hormone secretion, brain activity, visceral organs, muscles and even the pupils of her eyes, and so on. There will be corresponding changes, although these changes in physiological responses may seem subtle, obscure, and complex, but they are psychological program.

\subsection{GENERAL PROGRAMS FOR DEPRESSION}

Any person who encounters an unsolvable event produces a physiological response to depression, such as "anxiety", "unease", "bad", "disappointment", "depression", etc.

When a person craves something and wants to take action to get it, his body physiology will have a desire for it, and there will be some physiological reactions related to it. At the same time, the body needs energy to act, body triggers a series of physiological responses, dopamine secretion, adrenaline secretion, increased brain oxygen supply, a person who feels energetic, quick thinking, high mood.

On the contrary, if a person encounters something that cannot be solved, and she thinks it is important, she will be finished if she does not solve it, so she will fall into the physical reaction of depression, the psychological and physical feelings of depression may include "cold body, powerlessness, despair, the body is suppressed by heavy objects, and deep down fear and fear of being unable to solve the problem." Etc.

These psychological and physical feelings are real, it is because the energy supply of physical activity is turned off, blood, epinephrine, dopamine, various organs, various endocrine activities are closed and weakened, so patients will feel powerless, cold and so on. Because the body energy supply is turned off or suppressed, and because the patient's attention has been on the thing that can't be done, the patient has no energy supply when doing other things, no interest in other things, depressed mood, serious symptoms of stiffness and numbness.

The "energy supply" here refers to "oxygen, carbohydrates, adrenal hormones, dopamine........." Etc, real physiological energy.

Depression is not only because the body shuts down the energy supply, but also for a very important reason, or a program. This is the belief: "if you can't do this, what's the point of doing something else?" and depression occurs when there is no energy supply, no interest and motivation to do anything else. This program can be represented as:(FIG 14)

As for why the body shuts down the energy supply and leads the patient to fall into the physical response of depression, that is, why people despair when they encounter insoluble 
events, which should be an innate genetic instinct, and it is also a psychological program.

We can use the mathematical expression "1" to start the energy supply, and the energy run is suppressed or turned off, called " 0 ", which is binary, which works the same way as a computer program.

\begin{tabular}{|c|c|}
\hline $\begin{array}{l}\text { When there is an insurmountable } \\
\text { event, and it is very important } \\
\text { (probably just that you think it is } \\
\text { very important), it is very serious } \\
\text { not to solve the consequences; }\end{array}$ & $\begin{array}{l}\text { Things can't be solved (it } \\
\text { may be subjectively you } \\
\text { can't, objectively you } \\
\text { can); }\end{array}$ \\
\hline & $\downarrow$ \\
\hline $\begin{array}{l}\text { Lack of strength and interest in } \\
\text { doing other things; trapped in } \\
\text { depression, depression occurs; }\end{array}$ & $\begin{array}{l}\text { The energy supply is } \\
\text { limited, and the } \\
\text { physiological responses } \\
\text { related to depression are } \\
\text { aroused; }\end{array}$ \\
\hline & \\
\hline $\begin{array}{l}\text { No physical energy to do other } \\
\text { things; } \\
\text { Think "can't solve this thing, do } \\
\text { other things don't mean anything? } \\
\text { ", lost interest in doing other things; }\end{array}$ & $\begin{array}{l}\text { The body is trapped } \\
\text { in physical reactions such } \\
\text { as weakness, cold, } \\
\text { stiffness, etc.; focus on } \\
\text { unsolved events; }\end{array}$ \\
\hline
\end{tabular}

FIG 14

\subsection{CAUSES OF MANIA}

When the patient has been depressed for a long time, some of her physisological reactions are suppressed by depression, and once depression is temporarily relieved for some reason, her suppressed physiological response runs violently. The depression and mania at this time can be regarded as the misrunning of the two programs.

\subsection{MODIFICATION OF DEPRESSION PROGRAM}

The root cause of depression is the inability to do something, which is very important and the consequences of failure are serious. Whether it is actually impossible, or because she lacks confidence and subjectively thinks she can't, it evokes physiological reactions such as despair and unease. The ability or inability to deal with these physiological responses determines whether or not to suffer from depression. If she can eliminate these physiological reactions through a series of actions, she will heal. (the words "despair" and "uneasiness" in 
this paper refer to the physiological response of "depression". These words are just representatives of the physiological response of "depression", and the whole physiological response of "depression" cannot be fully listed.)

If these "despair" and "unease" can not be eliminated, her body will be stuck in the "despair" and "unease" physiological responses. Therefore, the key to the treatment of depression is to be able or unable to eliminate the physiological responses such as "despair" and "unease"

There are two ways to eliminate physiological responses such as despair and unease:

1, to boost self-confidence. Believe that you can do it, and force yourself to do it with willpower.

There are two ways of doing this, one is that she is actually able to do it, but she lacks confidence that she can't do it subjectively, and then her character needs to be modified to build her confidence, and then she has the confidence to do it. "despair" and "unease" would ease when she had the confidence to do it.

The other is that something is really very difficult to do, but you can't give up. What happens? If he uses willpower to force himself to "do it," then there will be "anxiety" and "compulsion", that is, not depression, but also anxiety and compulsion. That is, depression and compulsion and anxiety are different coping strategies for the same thing. While raising confidence increases the likelihood of "doing it," there is also a risk of "compulsion" and "anxiety".

2, change the cognition and belief that "something is important", that is, do not think it is very important and must be done, give up "do, get", enhance psychological tolerance, accept reality, bear the result that can't be done.

The girl in the case was depressed because of her lack of family warmth, but she was not a serious depression.

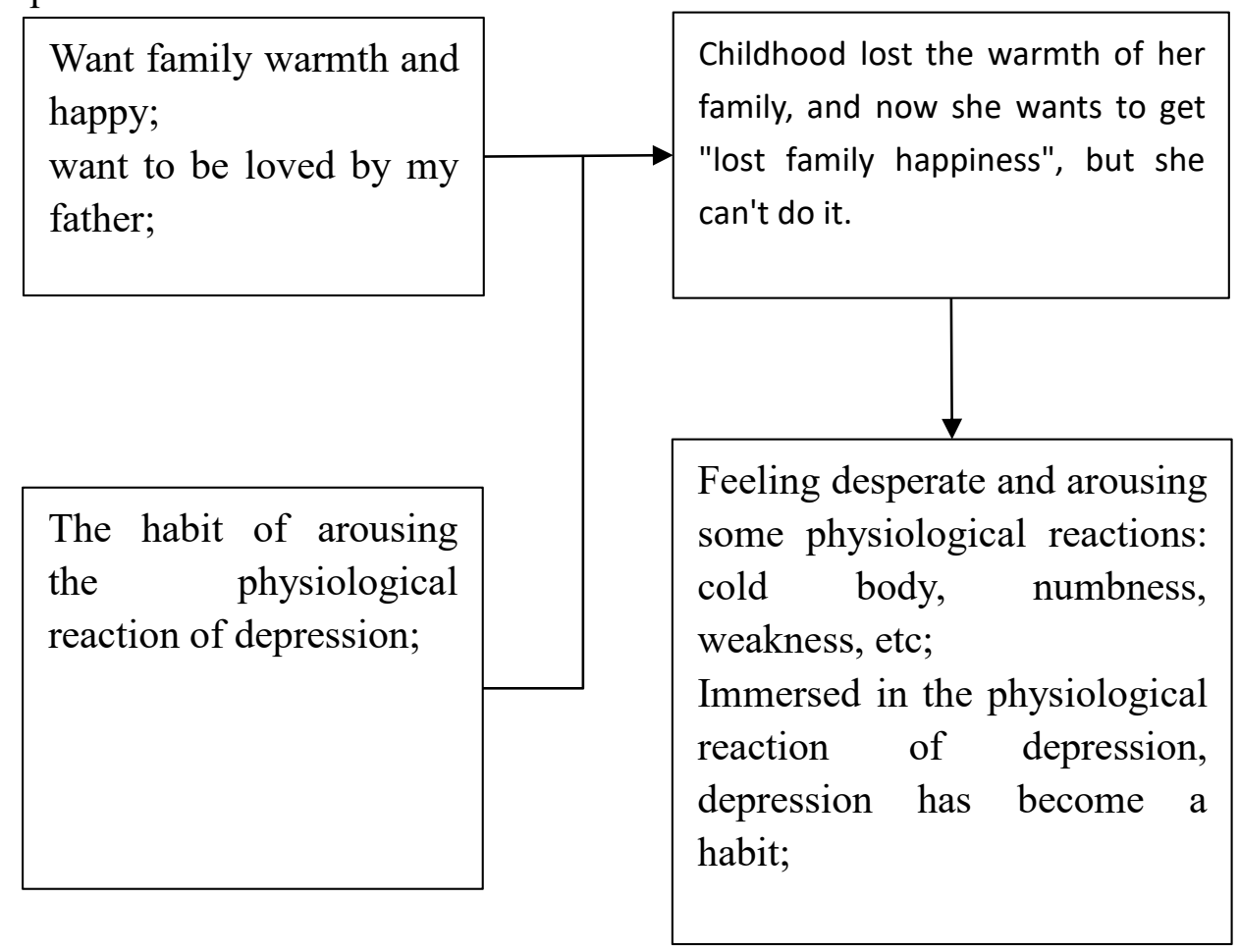


Fig. 11

But severe depression is not just depression because you can't do something, but it's stuck in some particular physiological response. If she is a severe, typical depression, then her psychological program is as follows, which is also a true depression program model(Fig 11):

If she is deeply convinced that she cannot do it, and she evokes a series of depressive physiological responses, such as: "the body is cold, the body sinks, the body is numb, the physical activity tends to stop (not really stop)." Is does not want to be active); "etc., [this paper is only speculating about these physiological responses, but has not yet been verified]. She was immersed in these physiological reactions and couldn't get rid of them, and that became depression.

Not everyone evokes these physiological responses when faced with things that cannot be done. This is related to individual personalities and perhaps to innate genetic psychological tendencies. Some people, when it comes to things that are difficult to solve, she keeps hinting at herself, "it's over, really can't do it," maybe it's because she experienced too many setbacks in her previous life, and she really believes she can't. And when they realize they can't, they evoke a physiological response to depression.

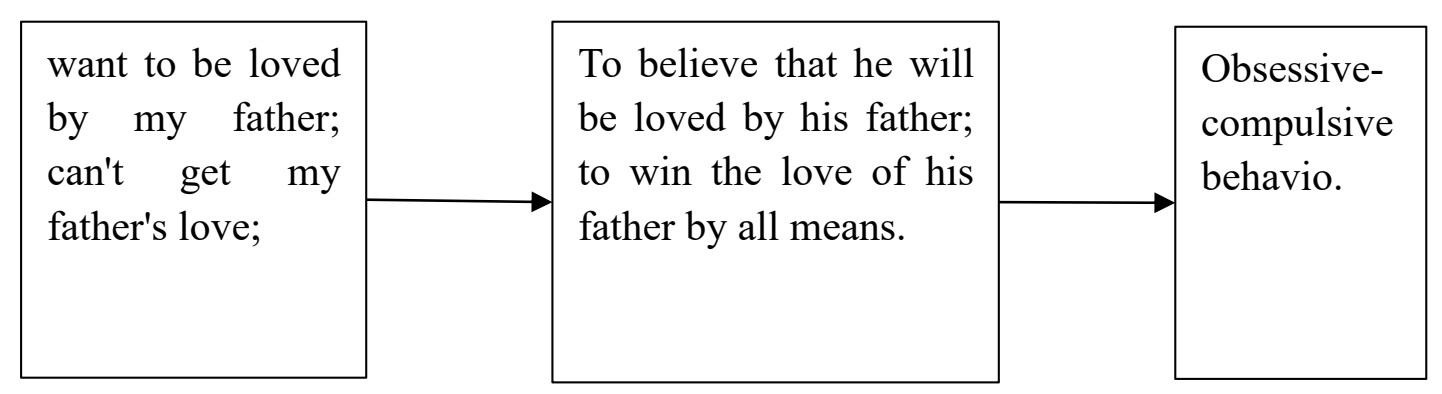

FIG 12

But when a healthy person believes he can't do it, he doesn't evoke these physiological responses, even if they do, they're not so strong, and he doesn't immerse himself in them. But depression patients not only habitually evoke them, but also immerse themselves in them. Some people react differently to things that are difficult to do, such as(FIG 12).

This kind of person's response is to boost self-confidence and force herself to do it. She doesn't "deeply believe she can't do it", and she believes she can do it. Although he does not suffer from severe depression, he may have other problems, such as compulsive tendencies and abnormal control of behavior. As a result, neither of these is a good way to deal with them, rather than a third. (FIG 13). 


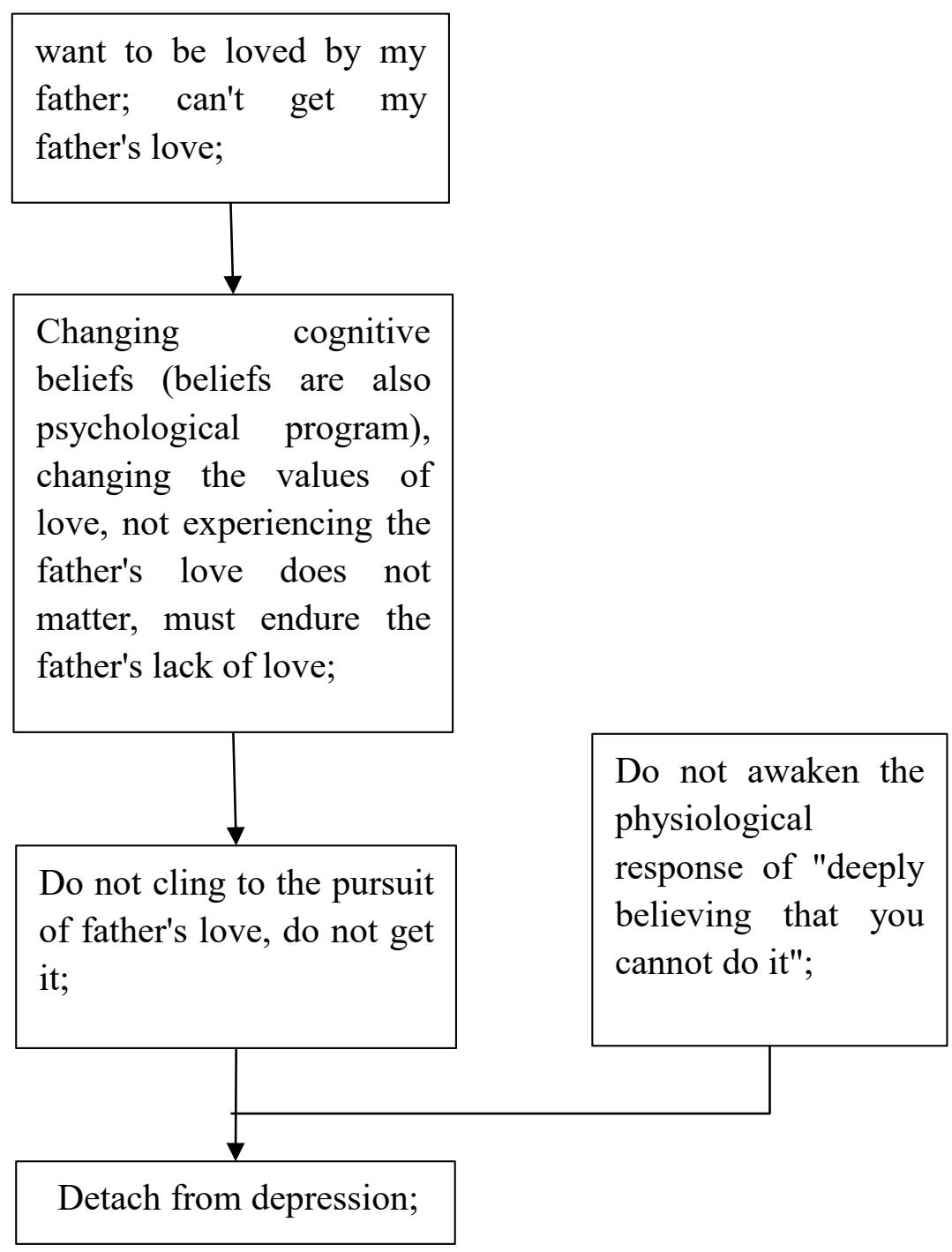

FIG 13

Of course, the above-mentioned "Can't get a father's love" is just an example, and the case of the previous girl is not only because of the lack of the father's love, but because of the lack of family happiness and warmth.

Pay attention to:

Although this case is fiction, the "depression program" is considered to be correct and the case is only used to show the "depression program".

\section{PERSONALITY PSYCHOLOGICAL PROGRAM}

This is a case of an introvert $(\mathrm{B})$ (real case):

"I am the third child and have two brothers. When I analyze the reasons for my character formation, I can strongly feel that my character is related to my second brother. 
I will also introspect and recall the psychological activities when I was with him. I have noticed that my eyes always look into his eyes, in order to read his mind from his eyes.

I always seemed to focus on his mind, his mind as the center, read his mind, know his mind at the time, can be targeted to determine their own behavior, can please him, make him happy, he happy, I happy, and I feel safe and happy.

This led me to do the same with others in the future, paying attention to their feelings and making them happy.

I seem to feed on each other's emotions, meaning I like to pay attention to their expressions. Experience her emotion from the other party's expression, the other party's emotion can infect me, the other party is happy, I am happy, the other party is not happy, I want to make her happy, so I also follow happy.

My second brother's character gave me the impression that he was mighty, aggressive and self-centered, not only in my family, but also in my village. They(second child) are mighty, brave and not afraid to clash with others.At the same time, he was self-centered.

$\mathrm{He}$ is very comfortable with me because he is very natural. Most of the time he's showing himself and does not look into my eyes too much to read my mind.

This is different from big brother, who would stare into my eyes, with the smell of insight and voyeurism, which made me very uncomfortable.

The second brother does not pay attention to my mind, he gives me the feeling of "self-centered", only pay attention to their own feelings, to use the theory of Freud, he is a "happy principle", his "id" seems to be very powerful.

Big brother's "superego" seems to be more powerful, more moral and "social norm".

Second brother is very overbearing, violence, often hit me, he is the kind of "warrior" type of person, not afraid of fighting, not afraid of conflict with others.

I, on the other hand, always seem to be other-centered, weak, timid, very afraid of conflict with people.

I'm good at listening, with others, always listening to others.

My character is the opposite of my second brother."

In this case, the patient used the method of introspection. By recalling the psychological activities of childhood and the second brother, he perceived the psychological activities of interpersonal interaction with the second brother and then described them in words.

"Introspection" is not only an important research method, but also an important psychological analysis method. Here, the psychological counselor guides the patient to recall and introspect the psychological activities of his childhood, looking for the psychological program of his introversion.

From his narration, we can see some implicit behaviors of his psychological activities, such as "I always like to look into his eyes", "the purpose is to read his mind from his eyes", "experience her emotions from her face" and so on. These are psychological procedures.

A psychological program is not a process or a step to solve a problem. It is a behavior, an implicit behavior in the body of a living being. It is not describing a "process", it is describing a "behavior, action".

The counselor summarized the client's introversion program from this description and subsequent counseling. The counselor then speculated about his brother's psychological program, based on his own vacuum-filling theory and previous studies of sibling rank and 
personality. The block diagram on the left of "figure 6" and "figure 7" below shows the character of the second brother.

These two internal and external program of personality are only those of the client and his second brother. The psychological programs of each person are not exactly the same, and there are individual differences between people. Therefore, each person's psychological programs need to be specific analysis, of course, the consultant based on their own experience, for some cases can be used to guess what kind of psychological programs he has.

Although each person is different, there are also "same or similar" programs. For example, the paper argues that every second-eldest boy in a Chinese family has a similar "extrovert program," which is not exactly the same but has a similar or similar structure.

\section{1 personality psychological program demonstration}

The personality program is a psychological program established after birth. It is a set of programs that the individual has actively or passively established from his life experience. Most of the personality is formed by the interaction and mutual adaptation between people, especially with the closest persons during childhood, such as the client in the last case and his second brother.

The block diagram contains some implicit behaviors, such as "guessing each other's mind "," focusing on their own psychological feelings ", and" looking at the other person's eyes ". Because these behaviors are more hidden, most of them are carried out in individuals, so they are called "implicit behavior ". In case A, for example, the girl "suppressed the urge to be angry," the implicit physical manipulation in the body is to run a mental program.

The extroverted personality that the client wanted is actually similar to his second brother's personality. What she did not establish is what his second brother has, i.e., an extroverted personality program. Therefore, the therapist's job is to let her learn part of his second brother's personality program, namely, the ones in Fig. 6 and the left side of Fig. 7.

In this case, the therapist combined Adler's theory about birth order with his long-term observation of the personality of siblings and personal thoughts and put forward two points to analyze the personality programs of the client and his second brother:

1. The personality of the second child (not invariably, but highly probable): self-centered, tough, cheerful, eloquent, focusing more attention on their own feelings while ignoring others' feelings and so on. This refers to the birth order of children in Chinese families.

2. There is a tendency to fill in the vacuum in each other's psychological spaces in personal relationships, and this is called the "complementary phenomenon." For example, in this case, the client lives with his brother long-term; when his brother is extroverted, he will be introverted - the psychological space just complements both actors, similar to meshing gears, leaving no gap in between. The psychological program between brothers is also "complementary." For example, if the brother pays attention to his own feelings, he cannot pay attention to his own feelings. He needs to pay attention to his second brother's feelinAs mentioned above, Fig. 6 cannot be rigidly used as a template to confirm the brother's personality program. The actual psychological program needs to be analyzed in detail. Not 
everyone who is a second child has the psychological program shown in Fig. 6, and even if the second brother happens to have the typical "second child" personality, there are no two identical leaves in the world, so each second child has specific differences in their personality programs that require specific analysis. Similarly, in true psychotherapy, the younger brother's personality program also needs to be further analyzed and understood in order to grasp his specific progragAccording to the "complementary principle" of point 2 above, the client's personality program is derived as above (Fig. 7, left). If he wants to have an extroverted personality like his brother, he needs to modify it to be like the psychological program in Fig. 7 right (i.e., Fig. 6 above).

The establishment of the psychological program is achieved by consciously manipulating the physiological responses of the body. Because the psychological program is established when we consciously manipulate the body's physiological response, the modification of the psychological program involves using different bodily manipulations to create a new psychological program. In Case B, the therapist asked he not to pay attention to he brother's expressions and not to think about his brother's mind; these are new manipulations of his body.

Only then can the two be in harmony.

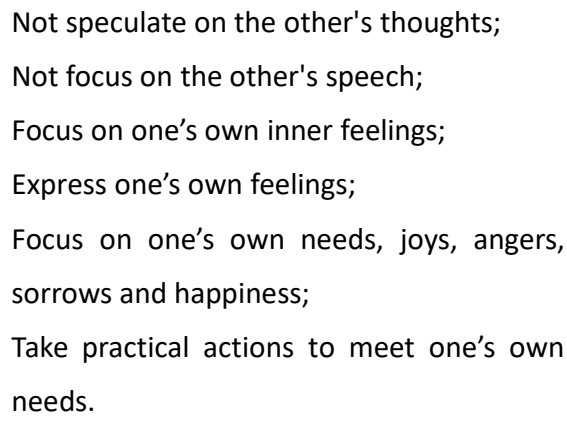

Fig. 6

\begin{tabular}{|c|c|c|}
\hline $\begin{array}{l}\text { Look at second brother's eyes and } \\
\text { face; (1) } \\
\text { Listen to brother; } \\
\text { Speculate on brother 's thoughts; } \\
\text { (3) } \\
\text { Focus on brother's feelings and not } \\
\text { one's own feelings; } \\
\text { Guided by brother 's needs; } \\
\text { Meet brother's needs with practical } \\
\text { actions }\end{array}$ & $\begin{array}{l}\text { Change of } \\
\text { consciousness to } \\
\text { manipulate the } \\
\text { body's physiology }\end{array}$ & $\begin{array}{l}\text { Do not look at the brother 's eyes and } \\
\text { face; (2) } \\
\text { Not focus on the other's speech; } \\
\text { Do not guess the brother's thoughts; (4) } \\
\text { Focus on one's own inner feelings; } \\
\text { Express one's own feelings; } \\
\text { Focus on one's own needs, joys, angers, } \\
\text { sorrows and happiness; } \\
\text { Take practical actions to meet one's own } \\
\text { needs. }\end{array}$ \\
\hline
\end{tabular}

Fig. 7 


\subsection{METHOD OF VERIFICATION OF PERSONALITY PROGRAMS}

Two subprograms can be seen in this case:

(1) Look at the second brother's eyes (in order to tell her thoughts) and face;

(2) Do not look at the second brother's eyes and face.

When running program (1), the client needs to mobilize a physiological response, i.e., to look at his brother's eyes with his "eyes." He must use his subjective will to control the movement of the "eye" organ.

However, when he runs program (2), he has to perform another operation of the "eyes." He may need to turn his head, look elsewhere, etc. and change the bodily operation of running program (1) to program (2), i.e., modify the psychological program and change his personality.

The changes in programs (1) and (2) are obvious from the outside, so the existence of these two programs can be confirmed by external observation or measurement of eye movement.

There are two more programs in this case:

(3) Guess the second brother's thoughts;

(4) Do not guess the second brother's thoughts; focus on her own feelings, desires, and psychological needs.

The physiological operation of these two programs is relatively hidden. When the client changes from running program (3) to running program (4), her changes to the manipulation of her body are difficult for outsiders to observe, but these two programs are indeed manipulations by willpower over the body's physiology - they are merely difficult to see from the outside.

Although programs (3) and (4) seem to be subtler to observers, the subjective feelings of the person may not be the case.

A precision instrument can measure the difference in physiological responses brought about by programs (3) and (4).

Here is a theoretical scenario:

A single-parent mother and a daughter, a typical "second-child character," because of the single-parent family, mother and daughter are very close, because some, according to the" vacuum filling principle ", the daughter's personality is as likely as the "third child's character" in the above case, is also introverted passive personality program, can be verified by the physiological measurement of her is this psychological program.

Mother and daughter are having a meal together. In the past, the mother always talked about her work, but today she is silent, and the daughter feels uneasy, so she runs program (3) 
to guess her mother's thoughts. At this time, her brain activity increases, so the amount of blood supply to the brain is inevitably increased, and the blood supply to the stomach is reduced.

If she runs program (4) and a favorite tofu dish happens to be on the table, she will focus on the joys of enjoying the tofu dish. Now, the blood flow to the stomach must be greater than when running program (3). At the same time, because she does not guess the mother's thoughts, her blood flow to the brain will be less than when running program (3). Therefore, by measuring the blood flow to the brain and the stomach in both cases, it can be seen that she is running two different psychological programs. Although when she runs these two programs, her external behavior does not seem to be very different, i.e., she is sitting there quietly, her physiological reactions are very different.

The establishment of a psychological program occurs through the operation of a series of physiological activities - conscious or unconscious - in an individual's life and the formation of habits and fixed patterns. In this case, "looking at the mother's eyes and face," "listening to the mother," and "guessing the mother's thoughts" are a series of physiological operations that combine to form an abstract "psychological program". This pattern of physiological activity can be changed into another by the conscious and active manipulation of the client.

"Speculate on mother's thoughts" It is a psychological activity, but also a physiological activity. Although the physiological activity of "Speculate on mother's thoughts" is weak and hidden, but it is a physiological activity. This case illustrates that the introverted personality represents a series of physiological activities (Fig. 7 left), whereas the extraversion type represents another series of physiological activities that are almost opposite in operation (Fig. 7, right). Therefore, changing the combination of physiological activities in Fig. 7 (left) to that in Fig. 7 (right) is to change the personality.

\section{THE PSYCHOLOGICAL PROCESS OF AUDITORY HALLUCINATIONS}

Here's a real case of schizophrenia.

Counselor: when did you notice symptoms?

Guest: I got it in 2015.

Guest: well, there are many side effects of taking medicine.

Counselor: suddenly hearing voices?

Counselor: did anything happen in your life at that time?

Guest: At that time, I stayed at home for a month because I failed the exam. I could not eat well and was ill without anyone to take care of me.

Counselor: what is the content of your hallucination? What do you hear?

Guest: hear others talk about me, scold me "camouflage".

Counselor: how old were you? At that time.

Guest: 24, 5 years old.

Counselor: did anyone ever scold you that before you heard your voices?

Guest: yes, rarely.

Counselor: are you worried about being called "camouflage"? 
Guest: I just feel bad.

Consultant: are you worried about that people say you camouflage?

Guest: I'm worried.

Consultant: that is to worry too much about others saying so about themselves, because the strong worry, induces the hallucination

Guest: can put it this way.

Guest: when the disease like a frightened bird, feel where is not safe.

Guest: everyone scolds you, you can understand?

Counselor: examine your behavior and see if it's considered a fake.

Guest: no disguise.

Guest: not really be scolded, it's an illusion.

Counselor: but you're worried about being scolded, and then you hear voices?

Consultant: if someone really wants to scold you like this, why do you think it is?

Guest: I didn't pretend!

Guest: But it has nothing to do with my behavior.

Guest: If you don't understand, forget it.

Consultant: I analyze, to eliminate every possible reason, it is not so fast to find the reason, this is the same as detective case.

Guest: besides scold me to pretend, some say they love me, this also is my behavior reason? You analyze the reason why others not only scold me, but also say they love me. I think it is better to find the reason from my psychology than from my behavior.

Counselor: what are the psychological reasons?

Guest: The more afraid I am of being scolded, the more you fear, the more it will happen.

Consultant: right!

Counselor: it's not that you're faking it, but you're afraid people will say you're faking it.

Guest: well, I'm timid.

Consultant: when you were a child, does anyone around hate someone else's disguise?

Guest: being scolded is only part of it.

Guest: there is a feeling of being seen through in the heart, what is in the mind to be known by others.

Counselor: afraid of being seen through?

Guest: and fear of being monitored.

Counselor: you always have secrets?

Guest: who's not?

Counselor: are your parents over-focused on what you're thinking?

C: not much.

Consultant: in fact, people have the right to "pretend" and "hide the heart".

Guest: by the man say love me, by the woman scold camouflage.

Guest: I am a gay.

Consultant: do you think "camouflage" is a big weakness?

Guest: maybe, and "stupid".

Counselor: are you a boy or a girl?

Guest: boy.

Consultant: are you afraid of being scolded camouflage by girls? 
Guest: when it's serious, it's more girls'voices.

Guest: can't sleep at night, it's all scolding. I couldn't sleep all night.

Counselor: that's serious.

Guest: in the heart scold. But he didn't open they mouth.

Guest: that was the most serious thing. It's gone now.

Counselor: do you behave differently from other boys?

Guest: no. I don't like girls.

Counselor: are you serious with girls?

Guest: nervous.

Counselor: you've always been gay?

Guest: no.

Counselor: when was you gay?

Guest: at the age of 13 .

Counselor: why are you worried about people scolding you?

Guest: I care about what others think.

Consultant:

Counselor: why do girls scold you more?

$\mathrm{C}$ : maybe I think girls are scary.

Counselor: when you became gay, were you worried about being scolded gay?

Guest: afraid, but no such illusion.

Counselor: 2013 years ago, were you afraid of being scolded?

Guest: I used to care about others' opinions.

Consultant: at that time afraid afraid others scold you "camouflage"?

Guest: at that time,I have not heard of "camouflage" this word.

Guest: once.

Guest: others scold me.

Consultant: 2013 years ago?

C: yes. When I first got into college.

Guest: scold me to pretend. He doesn't know me.

Counselor: the scolding was fierce?

Guest: no. He talked about me with others.

Counselor: this will upset you more than swearing in your face.

Guest: rightness, others scold me I also won't resist.

Counselor: have any girls ever scolded you that like this?

Guest: no.

Counselor: when was the first time you heard voices?

Guest: At that time in the university dormitory, I heard someone talking about me.

Guest: At that time on the street all people scold me, I hide everywhere, I want to hide in the hotel, a person is ok.

Counselor: the first time?

Guest: but there was also a voice in the hotel. I turned on the TV and found it was also the voice scolding me. Well, the first time.

Counselor: are you suddenly hearing voices? Did a lot of people know you were gay? At that time. 
Guest: they don't know. The people in the dormitory don't know.

Counselor: "it was in my dorm room. I heard someone talking about me." Is this auditory hallucination or is it real?"

Guest: now I think it is auditory hallucination, because later the next day I found walking in the street people scold me. He has been ill ever since.

Consultant: were you often scolded when you were a child?

Guest: no.

Counselor: the first hallucination, what happened in life?

Guest: Nothing happened. I just stayed home alone for a month with no one to take care of me.

Consultant: when you just read university, that classmate talk about you, say you "camouflage", that is not hallucination?

Guest: no.

Counselor: a month at home? What to do?

C: flunk. Review at home. May be due to overuse of my brain.

Consultant: were you not often scolded when you were a child?

Guest: no.

Counselor: when you grow up, why are you so afraid of being scolded ? Especially scold "camouflage"?

Guest: fear of it happening, it may not happen. Because I'm taking my medicine now, I have no hallucinations.

Consultant: ok, because failed the exam, is the pressure very big?

Guest: big, I thought it was a big deal to fail in the exam, because I had to repeat it.

Consultant: and then, no one cooks for you?

Guest: yes. My grandmother said she would cook for me, but I was so stressed that I didn't want to eat at her house.

Counselor: do you think your illness has anything to do with flunk?

Guest: yes.

Counselor: stressed out, anxiety and tension and thinking someone is scolding you?

Guest: It turned out that I fell ill just a few days before the examination resumed. When I was a sophomore, I left school and didn't go to college.

Counselor: what do you think your illness has to do with flunk? You analyze it.

Guest: at that time the pressure is extremely big and the body is weak, so produced the illusion.

Counselor: why hallucination is "scold you", not hallucination other?

Guest: I don't know.

Guest: There is one reason.

Counselor: come on.

Guest: I read a book called "the thick-skinned and dark-minded".

Consultant:?

Guest: The book says that if you want to be successful, you must learn to pretend, and don't be afraid of being scolded. At that time, maybe I was too eager to succeed.

Consultant: when did you read it?

Client: senior three. 
Counselor: then it must have something to do with your illness.

Guest: yes.

Counselor: you think flunk is failure, and then "if you want to succeed, you're not afraid to be scolded"?

Guest: that's right.

Guest: I don't think "the thick-skinned and dark-minded" is a good book. Probably because I didn't understand.

Counselor: let me think.

Guest: tell me.

Consultant: these things are connected, the analysis should soon find the crux.

Counselor: Do you want to be scolded like that?

Guest: yes, I want to succeed.

Counselor: let people scold on purpose?

Guest: yes.

Counselor: Want to be scolded?

Guest: yes.

Consultant: "if you want to succeed, you must don't be afraid to be scolded." that's what the book says. When you failed in the exam, you failed, so you have to compensate: must succeed! to succeed you have to not be afraid of being scolded. You deliberately created the situation of being scolded. You think you'll succeed if you get scolded at?

Client: at that time, I had this idea in the middle of my first auditory hallucination.

Counselor: you were misled by that book.

C: well, tell me your opinion.

Consultant: when you failed the exam and failed, did you suddenly have a force in the face of adversity: I want to succeed!

Guest: yes.

Consultant: there is something perverse about this power. It wasn't the book, it was the force of your compulsion.

Guest: yes.

Counselor: use willpower to tell yourself, "I must succeed."?

Guest: yes.

Consultant: where there is a will there is a way, eat bitter in bitter, to be the upper class.

Guest: yes.

Consultant: tell yourself with iron will that you must succeed. You can't motivate yourself like that. You can't force yourself to succeed. Your will will run wild.

Guest: yes.

Counselor: are you using willpower to push yourself crazily to succeed?

Guest: yes.

Consultant: then, you fantasize that "if you not afraid to be scolded, good at camouflage, and you will succeed." Your mind is wrong here.

Guest: I see.

Counselor: because you fantasize about "if you not afraid to be scolded, and you will succeed." 


\section{Guest: yes.}

Consultant: am I right in my analysis?If not, you have to say it.

Guest: Your analysis is correct.

Consultant: really?

Guest: I think so, too.

Guest: So I have no motivation to do anything now. I think I will fail at anything.

Consultant: lost confidence?

Guest: yes. Because of this failure, I feel that nothing can succeed.

Consultant: you are too afraid of failure and too eager to succeed. The more you want to succeed, the more you fear failure.

Guest: I see.

Consultant: your previous failures have hit you too hard.

Guest: yes.

Consultant: Set some realistic goals, for example, take an adult college, or learn a skill, after all, you also read a sophomore, learn a similar skills can be. But this time, pay attention to the point, again failed, also do not force yourself, failed to fail, do not desperately force yourself.

Guest: ok.

Like the previous case, the "auditory hallucination" program in this case is the psychological program of this patient. Not all "auditory hallucination" programs are like this. It is only the "auditory hallucination" of this patient.

In this case, you can see that the counselor's counseling process is like a police investigation, and the patient's narrative is confusing.

At the beginning, the patient described the auditory hallucination as "someone scolded him camouflage", So the consultant assumed his sticking point was because he was too worried about being scolded for pretending. The patient then becomes too sensitive to "other people's scolding" to induce hallucinations. Therefore, So the consultant asked the guest:"Are you afraid of being scolded for being 'camouflage '?", to test his hypothesis.

Then, asked him at home in his childhood "is there anyone who hates "'camouflage'? ", repeatedly asked him "when you were a child, did anyone often scold you?, want to know whether he has childhood to scold by the person "camouflage" trauma, but later discovery is not.

The counselor then wondered if it had anything to do with "gay" and asked him, "are you worried about being called gay?"That's not what happened.

Consultant has no clue, asked the guest what he was doing when he stayed home for a month for failing the exam. The patient replied, and the Consultant intuit that it might have something to do with "the pressure to failing the exam," and asked him to analyze for himself, "Does failing the exam have anything to do with hallucinations?" . The patient replied," too much stress and weakness, so hallucinations."

At this point, the consultant still did not find the crux of his problem, and naturally asked a: "why hallucination is 'scold you', not hallucination other?"

This time, it got the patient thinking, or "introspection," and the patient volunteered something that might have something to do with the psychological problem: " I read a book 
called 'the thick-skinned and dark-minded'."

The consultant said to him this is very confused, but guess he volunteered to say, should be a clue, then let him continue to say, the patient said: "the book says to succeed must learn to pretend, and do not be afraid of being scolded. Maybe there was too much desire for success."

At this point, the mystery was finally uncovered, the patient is thinking: "if you want to succeed, you must don't be afraid to be scolded."

So, ask him again: "when did you read it?"

The patient answered "senior three", and the consultant asked this question was to determine whether his auditory hallucination was after reading the book and to determine the causal relationship between the two. When he answered, "senior three" the counselor was almost certain it had a lot to do with his hallucinations.

The latter question tested the hypothesis that the patient "wanted to be scolded 'camouflage'." , and then fantasy someone scold themselves "camouflage", because to succeed will be "camouflage", also not afraid of being scolded.

Patients are their own deliberate fantasy was scolded and created auditory hallucination.

From this consultant's consultation, we can see that psychological counseling is like police investigation, we need to find out the psychological crux of the patient, this process is "psychological analysis".

Psychoanalysis does not only refer to the analysis of the psychological activities of patients, but from the beginning, counselors from all directions with a variety of methods (inquiry, sand table, room tree, psychological testing, etc.) to find the psychological crux of the patient's behavior, these are all psychoanalysis.

From the psychological activities of patients, we can see some psychological procedures, such as "want to succeed", "think success is not afraid of being scolded", "to succeed, have to pretend". These are his from the book of "the thick-skinned and dark-minded",

When he suffered a setback in the university, he wants more success, he needs more success, to make up for his failure. So he was fantasy that being scolded will succeed, will "camouflage" will be successful. Because he wanted to succeed too much, he began to imagine being"scolded" in his head. When he did so much, he really hallucinated being scolded.

The psychological program of the patient is represented by a block diagram, as shown in figure 10. 


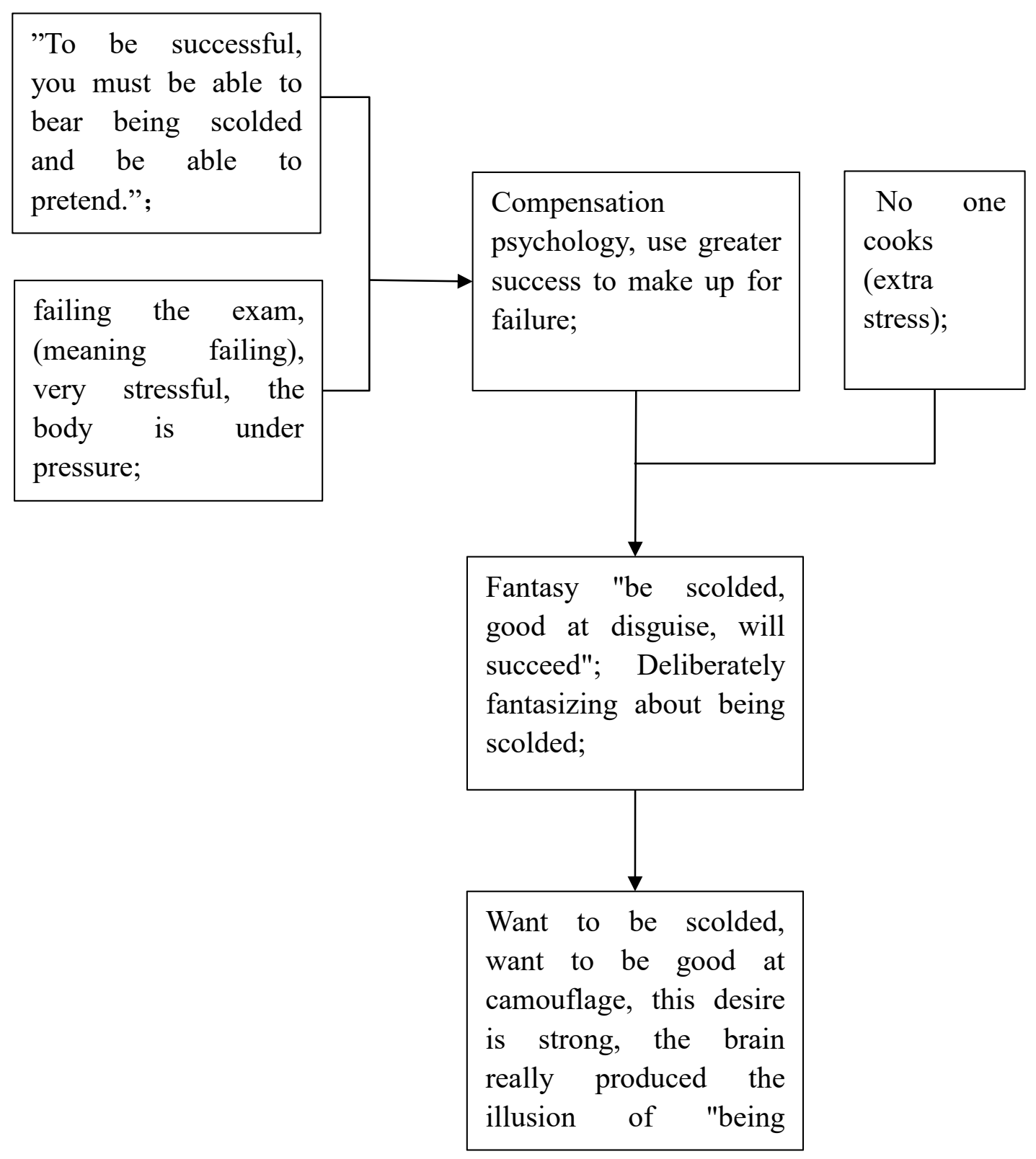

Fig 10

"Fantasy was scold camouflage" this is a program, that patients in order to "success", so "Fantasy was scold camouflage". In establishing this program, there must be a perverse power in his mind, this power is also to the failure of the exam resulting in a will to succeed namely compensation (the "psychological compensation" program), "the more you fail the more you want to succeed", so his mind went wrong, which is running the wrong program:"Fantasy was 
scold camouflage" and fancy that it would success, but that's schizophrenia and he shouldn't be running the program.

When his body evokes the "compensating power of perversion" that must succeed, he should control it so that it does not provoke the "Fantasy was scold camouflage" program to run.

Before hearing voices, just before 2013, the patient had a fantasy that, as in the "the thick-skinned and dark-minded", "if you can endure being scolded, you're good at pretending, you will succeed." Such psychological activities, such illusions are of course wrong programs, when he failed the exam, he thoroughly believed: "if you can endure being scolded, you're good at pretending, you will succeed." So he set up an even more faulty program: imagining, that someone was scolding him. When he is too eager to be scolded or because he imagines being scolded more, the brain really produces the sound of "people around him are scolding themselves" in line with his psychological expectations, and the hallucination occurs.

It's about the function of the brain, and for the brain, what people let it do, it does. When you want something strongly, but the reality doesn't satisfy your desires, the brain in order to protect your body will not collapse because of this strong desire not satisfied, will create a false, what you want, namely the illusion.

Here, the "compensation program" is very important, it's not clear where this came from, it's probably a human innate program.

"if you want to succeed, you must don't be afraid to be scolded." He learned it from the book, which according to the theory of cognitive psychology is "belief" or "thinking", but in fact "belief" and "thinking" are psychological programs. Patients also "install" such programs for themselves.

In the psychological activity of the patient, he is through a series of implicit behavior operations, that is, running a series of psychological procedures, thus produced auditory hallucination, auditory hallucination itself is a psychological program.

Therapy, of course, is refraining from running "a program of imagining being scolded." , but also to control "more failure will be more successful compensation psychological procedures."

Psychotherapy is through the analysis and awareness of the corresponding psychological procedures, and then the patient through the regulation of the corresponding psychological procedures to cure.

The key to psychoanalysis is to find the corresponding psychological procedures or implicit behavior, such as in this case, "more failure will be more successful compensation psychological procedures."

\section{MENTAL PROCEDURES FOR PATIENTS WITH DIABETES INSIPIDUS}

This is a real case. The following is the patient's self-description:

"I'm anxious, my life is stressful, I'm constantly thinking about the way out, but recently I've added a new problem. I had a lot of urine, and I doubt how much water I drink, and much urine I discharge, and the hospital checked that there was no organic problem.

Urine is a lot, but very clear, and the color is different from yellow, just like the water I drink.

According to your request, I introspective detection, that is, every time a lot of urine, I 
always in a very anxious time.

I feel, at this time my body has some "acid" "tired" feeling, feel the waist there, seems to be the bladder above, seems to be inside a "tube" some acid, itch feeling, then feel a lot of urine in the bladder, go to the bathroom, as expected pulled a lot of urine. This feeling is very weak, also do not know is acid, itch, anyway some different from ordinary feeling.

And before that, I was very anxious, and then something happened to my body, and then I had a 'sour, itchy' feeling, and then I urinated a lot."

In this case, the patient perceived the physiological response process of "diabetes insipidus" through introspection. The description may not be accurate, but it should be true.

When he is anxious, his body changes and he feels "tired, sore and itchy" in his waist. This is a new psychological program. At this point, when the urine is hypersecretion, we can regard this "hypersecretion of urine"as a program. The program was brought about by other programs that the patient ran while he was anxious, not by him.

We can't really observe this program from the outside, but the patient's subjective feelings indicate that it is a program in progress.

If we use advanced medical instruments to observe and measure the physiological response of the waist at that time, it may be the kidney, it may be the bladder and so on, there should be abnormal physiological response.

Treatment is to tell the patient to control their anxiety, when anxiety, his body changes, that is to have "acid, tired, itching" and other feelings before the way to not so anxious, not to let their body next reaction. That is to control the processes that keep "hypersecretion of urine" from getting started and running, as well as the anxiety program.

\section{CAUSES OF MENTAL AND PSYCHOLOGICAL DISEASES}

\subsection{DEFINITION OF "PSYCHOLOGICAL PROGRAM"}

Psychological programs can be roughly understood as implicit behaviors, but they are still different. Implicit behavior can be a "running psychological program," but not a "psychological program." Running psychological program is implicit behavior, but psychological program itself cannot be called implicit behavior directly. Moreover, people may have different understandings and definitions of "implicit behavior". In order to avoid misunderstanding, this paper redefines the concept of "psychological program":

Psychological program is not only the link between mental psychology and body physiology of human beings or other life, but also the link between individual mental psychology and external things. Psychological program is neither a thing in the physiological category nor a thing in the spiritual category. It is a combination of a series of steps in the effect of the spirit (or consciousness) on physiology. In order to perform certain tasks, life bodies need to initiate a series of psychological or physiological activities, which is the process of psychological or physiological activities called "psychological program".

This paper argues that any psychological activity or psychological phenomenon is caused by the corresponding physiological activity, Therefore, the definition of psychological program can also be regarded as only a process of physiological activity.

The source of psychological program is evolved and acquired by organisms in order to adapt to the environment and meet their own needs. Organisms are establishing and abolishing psychological programs all the time, and every living body is running 
psychological programs. The psychological programs of each individual are not exactly the same, but some individuals have similar psychological programs.

Everyone runs different psychological programs, but there are the same or similar. "there are no two identical leaves in the world." even the two leaves on the same willow tree are different, but they are the same or similar, because they are all willow leaves. The same is true of psychological programs. A certain psychological program in everyone is not exactly the same, but there are similarities. For example, the "introverted character" program, the "introverted program" of two introverted people will not be exactly the same, but they are similar, because they are "introverted programs".

some examples of psychological procedures:

"defecation."

"Defecation" is a psychological program. When we take the bus, we suddenly want to poop, but the car has not yet arrived at the station, so we can only bear, this is the consciousness in the control of the "poop" psychological program, so that it does not run.

"Sex" is a psychological program, "eating" is a psychological program, and "thinking" is a psychological program. Human psychological activities, physical activities can be regarded as psychological programs, people's body is running psychological programs all the time. Mental illness will occur if the psychological program is misrun.

The above psychological programs are more obvious, but in psychology, difficult to understand a lot of psychological programs.

For example,

the "belief" of cognitive psychology is a psychological program;

"self-confidence and inferiority", they are psychological programs;

"character" is a psychological program;

"temperament" is an innate psychological program; Etc.

\subsection{IMPLICIT BEHAVIOR}

Here is also the definition of implicit behavior, the definition of implicit behavior: in order to perform certain tasks, life consciously or unconsciously manipulates the physiology of the body and provokes certain physiological reactions or activities. These manipulation of the body is called implicit behavior. It is not only these conscious or unconscious manipulation of the body, but also the automatic physiological activities of the living body, such as alveolar dilatation, heart beating, and even the binding of oxygen molecules to hemoglobin.

\subsection{PHYSIOLOGICAL RESPONSE.}

With respect to the physiological response, it is necessary to include a variety of emotions, and the "to grieve with joy" is a physiological response, and the emotion itself is a psychological program. People's "be happy", this "be happy" is the psychological program, the "exhilarating" is also the psychological program, the "depression" is also the psychological program.

The operation of psychological programs can produce various physiological activities and physiological responses, some of which are subtle.

For example, the later case $\mathrm{C}$ of forced thinking, in which the patient's "brain is emptied" is some physiological response, which is caused by his running the "forced thinking program". 
In case A above, the patient's "tight body and chest pain" are also caused by poor psychological procedures.

Some of the physiological reactions or physiological feelings brought about by the running of psychological programs are difficult to describe and describe. For example, visitors with introverted personality describe: "when I face others, the body seems to be 'concave' in the same way. I feel that my second brother gives me a feeling of 'convex', like a 'convex field' squeezed at me." here, "convex", "concave" is the physiological feeling he describes. This paper believes that these subjective feelings are real, it has a physical response. This kind of physiological feeling is also called "physiological response" in this paper.

People perform different tasks, such as eating and sexual activities, which trigger different physiological responses. Eating, people's eyes see food, mouth will secrete saliva, nerve release pulses, gastric acid secretion, etc. This is a group of physiological reactions, sex, eyes see the opposite sex body, sexual organs congestion, expression excitement, etc. This is another group of physiological reactions, obviously, the two groups of physiological reactions are different, this is two different psychological program. If because of what factors, disrupt and destroy the combination of these physiological reactions, such as anorexia is because the psychological program of "eating" is disrupted, patients because of anxiety about body shape, suppress the "eating impulse" for a long time, "eating impulse" is suppressed or even forgotten, so anorexia. The same is true of sexual dysfunction. If an individual is strongly frightened during sex, the physiological response to sexual activity is disrupted.

Note that the "physiological activity" referenced here is not a psychological program. The abstract combination of physiological activities is a psychological program; these "manipulations" may be conscious or unconscious, and these "tasks" refer to tasks that a living organism wants to do, e.g. eating or moving an object.

The psychological program is the link between the mental phenomena and the physical physiology of human beings or other life forms as well as the link between the individual's mental psychology and external affairs. The psychological program is in neither a physiological category nor a spiritual category. It is a combination of a series of steps of the impact of the mind (or consciousness) on physiology.

To perform certain tasks, the living organism needs to manipulate the body consciously or unconsciously. For example, if the client in Case A wants to achieve psychological balance and security through "forced anger," she needs to control her own body and carry out a series of physiological activities that are the manifestations of the subjective initiative of consciousness. These manipulations also include actions such as arousing, strengthening, and weakening the physiological responses of certain organs. For example, when the client in Case A is "angry", the corresponding nerve center will send nerve impulses, and the lungs will accelerate the breathing rate. These "actions by consciousness on the body" are combined following certain orders, rules, time intervals, intensities, etc. This combination is called a "psychological program". Of course, a "physiological response" itself is not a program; it is only the manifestation of the program. The "psychological program" itself is abstract, much like the physical concept of "time" that we set up to better understand the world.

Walking serves as another example. When we start the "walking" psychological program, the cerebral cortex sends nerve impulses to command the muscles in the thighs to contract in order to lift the legs, and this command that makes the thigh muscles tense is the 
psychological program.

The act of thinking is also a psychological program. Thinking requires the brain's nerves to carry out activities. It also requires other physical parts, such as the eyeballs, increased blood supply to the brain, and reduced blood supply to other organs. The command for the eyeball to turn to the left, right, or up is also a psychological program.

The same "physiological response" may belong to a different "psychological program." For example, the physiological reaction of "increased adrenalin secretion" may be caused by "anger" or the excitement of "hunting."

Programs running only in a specific individual's body, as in the aforementioned cases, can be narrowly regarded as psychological programs.

\subsection{NORMAL AND PATHOLOGICAL PSYCHOLOGICAL PROGRAM}

The acquired psychological program should be compatible with the innate genetic psychological program. All kinds of physiological reactions and psychological needs of the human body are genetic programs.

The psychological program that has been established can work well with genetic physiological functions, will not cause damage and pain to the body, can adapt to the outside society, and can meet the physiological and psychological needs of the individual. Such a psychological program is a normal psychological program.

On the other hand, the operation of a certain mental program can cause obvious damage to your body and physiology, or damage to other things outside, such as abnormal killers, people with antisocial personality disorders, to others or to their lives. This psychological program is a morbid psychological program.

Psychological programs can also be divided into systematic psychological programs and applied psychological programs.

There are many types of physiological responses to psychological programs, as mentioned earlier, not just the physiological responses of specific physiological organs (such as adrenal physiological responses, or lung, heart, muscle, etc.). For example, there is a psychological program, which is the manipulation of consciousness to the whole of the body, which is an implicit behavior.

In the case of depression mentioned above, when a person wants to initiate an action to do something, the body as a whole acquires physical energy, and when depressed, it shuts down the energy supply.

In fact, this activation and shutdown of body energy does not occur only in depression. This activated and closed body manipulation occurs when people start doing something and decide not to do something. For example, when a person was watching TV, he suddenly decided to go for a walk.

The shift from watching TV to going out for a walk. When watching TV, his body and physiology are in a set of reaction patterns. When he decides to go for a walk, he will first turn off the psychological program of "watching TV." Turn off this set of physiological activity patterns when you run the program, and start the psychological program of "get out of the house, take a walk," that is, start another set of physiological activities. This "turn off" and "activate" body reactions are manipulation of the body by consciousness. In the operations of "turn off" and "start", the operation of consciousness to physiology changes the physical activity of the body, which is called "operating system psychological program". 
The manipulation of this consciousness to the body is the manipulation of the whole body. It is not the physiological activity produced by a specific physiological organ inherited by human beings, it is when the psychological program running on the body needs to switch. The physical activity of manipulation of the body when consciousness closes or initiates a psychological program.

Application psychology program: this is the program that life starts when performing a specific task. For example, when angry, "lung ventilation", "accelerated heartbeat", "adrenalin accelerated secretion" and other physiological response combination of the "angry psychological program", this program is "applied psychological program."

\subsection{HIERARCHY OF PSYCHOLOGICAL PROGRAM.}

Psychological programs and computer programs have the same grade, size, and size. The program to be analyzed in psychoanalysis is the program level that occurs in the individual psychological obstacle and the program at which the human consciousness can manipulate and modify. For example, in case A, "forced anger," the program of anger can be subdivided into "oxygen molecule movement in the alveoli," but it is clear that psychological analysis does not need to be analyzed at this level. Because her problem is not that "the movement of oxygen molecules in the alveoli" fails (if it is a doctor's job), and at this level the human mind has difficulty manipulating them. Nor is it meaningful to analyze these "larger" programs of social systems. The patient is the result of "interpersonal relationship" and "angry" program disorder, so analyze this level.

\subsection{CLASSIFICATION OF PSYCHOLOGICAL PROGRAMS}

Just as with words and sentences in human language, there are many kinds of psychological programs in mental and psychological activities: personality programs, confidence programs, sexual programs, emotion programs, food digestion programs, gymnastics programs, and so on.

Psychological programs are not limited to running within an individual. They also run between living organisms and between a living organism and other objects and things. For example, if someone beats another person, the beating behavior occurs between two individuals, but it is also a psychological program. When we are in the woods, stroking a tree trunk and listening to the sound of the wind blowing through the leaves, there is an abstract psychological program that connects us with these natural things.

Therefore, in a broad sense, at the macro level, a psychological program refers not only to the operation of our consciousness to control our body but also to our explicit behaviors, such as attending a meeting, going to a restaurant to eat, and interacting with a friend, all of which are composed of psychological programs; at the micro level, our physiological changes in the body, the discharge of nerve impulses by neurons in the brain, the transmission of nerve impulses, the release of chemical transmitters of sensory receptors, etc. also belong to the category of psychological programs.

The psychological program should be divided into consciously running programs and unconsciously running ones. Programs that are consciously run include examples such as deciding to see someone today and thinking about a problem; unconsciously run programs include secretion of stomach acid for digestion and becoming angry due to unhappy encounters. 
The psychological program can also be divided into innate and acquired programs. Innate programs are natural instincts, such as pupil dilation when in danger and saliva secretion when seeing food; psychological mechanisms and adaptations in evolutionary psychology are innate programs. Acquired programs are those that the living organism actively or passively establishes during life after birth, such as personality psychological programs. Due to the evolution of life, the innate program is usually corrected repeatedly and is usually not erroneous, but it may be used inappropriately, thus creating mental and psychological barriers. Acquired programs, on the other hand, are very error-prone, but they are also easier to modify.

People run all kinds of psychological programs all the time. These programs are related to each other, with hierarchies (such as priority, primary, secondary, and so on) and differences (such as conscious, unconscious, and so on). They work together and operate with certain rules; when these rules are disrupted, psychological illnesses will arise.

\subsection{CHARACTERISTICS OF PSYCHOLOGICAL PROGRAMS}

All life forms have psychological programs, which are combinations of actions that an organism uses to manipulate the body to accomplish certain tasks. However, the psychological program itself is an abstract thing, not an entity. It does not exist in nature, nor can it be said to be an ephemeral entity, lifeless and unable to control the body's physiology. It is consciousness that manipulates the body's physiology. In other words, consciousness establishes and runs psychological programs by manipulating the body's physiology.

\subsection{OPERATIONAL RULES OF PSYCHOLOGICAL PROGRAMS}

\subsubsection{SPONTANEITY}

Spontaneity refers to how the operation of a program is caused by a corresponding stimulation event that triggers an automatic physiological response. For example, in Case A above, the client's anger program is not a spontaneous reaction to the stimulus. Her obsessive-compulsive anger program is used deliberately.

\subsubsection{INTEGRITY}

This refers to how, after a spontaneous program starts running, it should end naturally. If it is interrupted by human intervention or accident, mental disorder will occur. For example, in post-traumatic stress disorder, when the patient faces a strong stimulus, his/her body instinctively initiates a series of programs: fear, nervousness, adrenaline secretion, pupil dilation and so on. These emotions evoked by these programs are so strong that he/she cannot deal with them immediately. If there are too many dangerous stimuli at a time, he/she will lose sight of the big picture and will have no time to run the various programs to completion. Thus, afterwards, he/she will get stuck in certain programs and forget how to run certain programs, and post-traumatic stress disorder occurs.

\subsubsection{DYNAMIC AND OVERALL CHARACTERISTICS}

The living body has a subjective, conscious will. When we consciously run a certain set of programs (referred to as conscious programs), because the individual's attention can only be concentrated on one thing at a time, that is, an individual can only run one conscious program at a time and cannot run two or more sets of them simultaneously, one mind cannot 
be applied to two tasks.

When consciously running psychological programs, the overall characteristic is running on the entire organism; when a person runs a conscious program and then runs another, there will be conflict and interference for the body's physiology. For example, when thinking about finding a job, one starts thinking about what to eat at the same time. This is an example of running another program while one is already running, and it can lead to a personality split.

There are overall and dynamic characteristics in running a psychological program. The phantom limb pain in amputated patients is most likely due to the operation of the original, complete psychological program. For example, for someone with an amputated leg who puts on a prosthesis and runs the program of "walking," his psychological program still includes the lost limb. Though this part of the limb does not exist now, his "walking" psychological program still has not changed and still continues to include this amputated leg. This may cause blood to resume its flow to the non-existent limb, and blood will be congested in the fracture, causing pain.

\subsection{PATHOLOGICAL CAUSES OF PSYCHOLOGICAL PROGRAMS}

\subsubsection{RELATIONSHIP BETWEEN PSYCHOLOGICAL PROGRAMS AND} PHYSIOLOGICAL RESPONSES

Physiological response itself is not a psychological program, but the running of the psychological program will arouse the corresponding physiological response or physiological changes. Psychological programs and physiological reactions are inseparable.

Organisms use psychological programs to manipulate the physiological activities of the body to accomplish certain tasks. The operation of the psychological program will arouse the corresponding physiological response, and the psychological program works by arousing the physiological response and physiological changes.

For example, when a person encounters a dangerous animal in the wild, he will start to run a psychological program to make the adrenal glands secrete hormones and make the muscles tense in order to flee or fight.

Because all of our mental activities run psychological programs to control the body's physiology to complete tasks (including consciously and unconsciously starting and running them), if an inappropriate program is used, errors occur in a program, or a program is used inappropriately, it will be physically confusing or ill effects will show, such as tension headaches, convulsions, mania, and hallucinations. These physiological reactions will bring pain to the living body, which is the root of the suffering of patients with psychosis and mental illnesses.

In fact, the derangement and madness of the psychopath is not a disease in itself. These deranged behaviors, such as "crying and laughing", "smashing objects" and "attacking others", are often caused by the disorder of the patient's physiological reaction, in order to alleviate the pain. Patients use these "crazy" behaviors to vent and relieve them.

\subsubsection{AN ERRONEOUS PROGRAM IS ESTABLISHED}

For example, in the obsessive-compulsive anger disorder (Fig. 1) in Case A above, the patient herself consciously established this abnormal program.

\subsubsection{DISRUPTS THE CORRECT PSYCHOLOGICAL PROGRAM.}

Some grass-roots psychological programs, due to the evolution of life, these programs have been revised over and over again, generally speaking, they will not make mistakes in 
themselves, nor will they cause disease. Our mental illness is due to the fact that we have made false changes to certain correct psychological programs. For example, the patient in case A changed the normal anger procedure himself (figure 2).

Of course, there are other mental and psychological diseases, such as depression caused by genetic factors, which can be regarded as congenital psychological programs for dealing with emotions are not good enough, but at this time need to change this innate psychological programs.

\subsubsection{THE PHYSIOLOGICAL RESPONSE INITIATED BY THE PROGRAM IS} EXCESSIVE.

The psychological program is composed of physiological response, and the corresponding physiological response will be initiated when the psychological program runs. If an individual runs a psychological program, the physiological response initiated exceeds the normal value, which can cause problems.

For example, a student is worried about the exam, normal people will start stress response in the face of the exam, there will be appropriate anxiety, in order to enhance the body's hormone secretion, blood supply, oxygen supply and so on. "stress response in the face of exams" is a psychological program that has physiological responses such as hormone secretion, blood supply, oxygen supply, heartbeat rate, etc., but if you run this psychological program, these physiological reactions are too strong. For example, strong worry about exams, extreme anxiety, that will initiate a stronger physical response, which may lead to physical and mental illness.

Because when an individual carries on a certain task, he or she starts the physiological response work by running a psychological program. If the intensity of the initiated physiological response is not appropriate, too strong or too weak, of course, there will be problems. Many post-traumatic stress disorders are caused by excessive physical responses initiated when the psychological program "dealing with risk" is run.

\subsubsection{THE PSYCHOLOGICAL PROGRAM IS IMPROPERLY INITIATED OR SUSPENDED.}

The psychological program cannot be suspended at will because of the "integrity" mentioned above. Widespread anxiety disorder, that is, anxiety disorder that does not have a clear object of anxiety, is inappropriate to initiate a psychological process of "dealing with dangerous or difficult events," because in the eyes of healthy people, there is no need to worry about or rush to deal with these events. Patients with anxiety disorder, on the other hand, appear worried, nervous all the time in order to cope with unexpected events, and his "dealing with dangerous and difficult events" program is overactivated.

\subsubsection{A CORRECT PSYCHOLOGICAL PROGRAM IS DISRUPTED}

Basic psychological programs are repeatedly revised by the evolutionary process, and these are generally free from errors and do not cause illness. Our mental illnesses are caused by erroneous modifications of some correct psychological programs. For example, the patient in Case A changed the normal anger program herself (Fig. 2).

Of course, there are other mental and psychological diseases, such as depression, that are caused by genetic factors; such diseases can be regarded as innate psychological programs that are not appropriate for dealing with emotions. It is necessary to change such an innate psychological program. 


\subsubsection{PROGRAM SPLITTING}

In fact, the symptoms and suffering caused by mental illnesses are more physiological, such as irritability, anxiety, and pain, and are not limited to the brain. Not only cognition but also all other activities, such as dreaming, interpersonal interaction, and reading, require physiological responses. For the treatment of non-organic mental psychological and mental diseases, it is more important to pay attention to the state of physiology outside the brain because psychological programs run more on the body, and the suffering of mental and psychological illnesses is more attributable to bodily factors. Psychological programs reflect their existence by manipulating physiological reactions.

The psychological programs that the human body generally runs are in the background. When running a program, other programs cannot be ignored, i.e., one cannot only focus on a single psychological program in a given time period.

The following is a case of compulsive thinking (C):

A patient with compulsive thinking reported that there was some numbness on the left side of the body and body odor from the underarms, while the right side was completely normal. He felt that his brain was "hollowed out". There was also numbness on the left side of the head, especially above the temple, and gastrointestinal problems such as constipation. This is because when he is compelled to think, the thinking not only affects the brain, but also, other parts of his body are acting physiologically.

However, when he needs to think through a certain problem, his eyeballs move to the upper right and stay this way for a long time. The eyeballs are turned upwards, showing the lower whites of the eye. This is part of his thinking process. However, when a normal person thinks, the eyes do not stay in this position for very long, and the movement also is not very pronounced. However, for him, to think through a certain problem, the duration and amplitude of the movement of the eyeballs to the upper right exceeds what is normal. It can be seen from this that his thinking process is somewhat different from that of average people. The numbness on the left side of his body and the pain on the left side of his head are all due to his running a different thinking program from others.

When healthy people think, some attention is kept on other physiological reactions, such as the urge to defecate, thirst, and the sensation of cold and warmth. However, the patient ignores or even suppresses these physiological reactions because he is too focused on thinking. In the upper level of the parent program of the thinking program, he should have retained some attention on other physiological sensations (such as the urge to defecate) and deal with these sensations in time, but he does not care about these programs and does not perform programs that deal with the physiological sensations. Therefore, he has symptoms like constipation.

The patient's error is that he does not have the correct thinking program. He separates the act of thinking from other physiological operations in the body and neglects urges to defecate, breathe, etc.; that is, his commandeers too much many bodily resources to support the act of thinking, which is the main problem. He once reported that because he was too focused on thinking, he was robbed of a mobile phone. He went to chase after the thief and fell. This was only because he lightly tripped over his foot. According to his own analysis, if he was not too focused on thinking at the time, his body would not be so uncoordinated and prone to fall. This shows that his thinking process has been separated from other psychological tasks and 
proceeds compulsively. This is program splitting.

Because he ran the "thinking program" improperly, he aroused physiological reactions such as "brain hollowed out", "numbness of the left body" and so on.

Here, you can compare two programs: 1 . Forced to think, forced to concentrate on a problem;

2. Let it go, what happens, and the brain thinks naturally;

This is obviously two different behaviors of physiological manipulation, and "1" is the patient's thinking program, it's morbid, and "2" is a healthy program.

These two psychological programs are implicit behavior, in fact, implicit behavior and explicit behavior can be changed. We can try not to drink, students try to correct their behavior in class, this is to change the explicit behavior, we can also bear not to miss someone, forced not to think of something, this is the manipulation of consciousness to the physiology, can change the manipulation.

The patient's mistake is not only to run the thinking program incorrectly, but more importantly, he should not be forced to think all the time, that is, he should not be running the "thinking program" all the time. The cure is to stop running this compulsive thinking program all the time, which causes his mind and body to split, his "thinking" and his body to split.

He should tell himself: there is nothing to think about, the problem has been solved, do not need to think about it, put down the thinking, let the body do things naturally. When a healthy person does something, his body naturally starts a "doing program". This program is not "always thinking". His attention is not always in the "brain" of the head, but in the body.

He has been forced thinking for so long that he has forgotten how to run the "doing" program, so he now needs to put down the "thinking" program, remember the "doing without forcing" program, and let his body recall its normal response.

His body is now trapped in the physical reactions caused by obsessive thinking such as "brain empty", "body tense" etc. He needs to stop obsessive thinking to alleviate these physiological reactions and remember the natural physiological reactions of doing things in the past.

He stops the forced thinking program to do something, and checks constantly to see if he's stuck in the program of forced thinking again. When he becomes aware that his mind is empty and his body is tense, he is back to forced thinking.

When he stops thinking, he goes back to the mode of bodily response that is activated by the body rather than by the "brain," and his brain doesn't feel "empty."

This patient had two procedural problems.

One is the forced thinking program, and the other is the "natural doing" program.

"Doing things naturally" is a program in which, when we're faced with an environment or a task, the body naturally activates some bodily response, and thinking is needed, but not in the way that the patient in this case thinks.

Forced thinking is a program, and what the patient needs to abandon is the program of forced thinking, the program of "natural doing," and then within the program of "natural doing," there is the program of "normal thinking."

\subsubsection{PROGRAM ERROR}

In Case B above, the client 's psychological problem may be due to errors in her 
socialization program.

\subsubsection{PROGRAM CONFUSION}

There are many psychological programs running in an individual at the same time; only one of these is run consciously. These programs run in an orderly manner during normal operations. Only after a consciously running program ends can another start. If some unexpected stimulus causes the next conscious program to be inserted before the previous conscious program has run to its completion, then the programs become mixed up and confusing, which can lead to mental illness, for example, post-traumatic stress disorder and psychosis (mental confusion, commonly known as "madness").

Because of her business failure, a middle-aged woman becomes confused, crying and laughing, speaking incoherently, sometimes hitting people, and sometimes apologizing. This is a psychological program disorder caused by a strong stimulus, and the program confusion in turn causes her physiological reaction to be disordered. However, crying, laughing, and beating people are not necessarily the physiological reactions of the psychological program itself but rather consequent to the physiological suffering caused by errors in the physiological reactions, and these manifested behaviors may alleviate these pains.

Program confusion differs from program error. The former is a process in which several programs are intertwined and entangled, causing mental and physiological confusion. The latter refers to a program itself being erroneous, such as the wrong anger program of Case A (Fig. 1). In Case B, if the client does not want her introverted personality, then the interpersonal relationship program (Fig. 7 left) is erroneous for her.

All kinds of psychological and mental diseases are caused by errors in these psychological programs. Neurosis, personality disorder, non-hereditary schizophrenia, and depression all emerge from errors in psychological activity programs. These errors can be artificially created, such as the aforementioned compulsive anger program (Fig. 1). Even if the program itself was wrong, making some changes to it, such as asking her to suppress the burning sensation, merely results in a new erroneous program: suppression of the occurrence of the burning sensation. This not only does not solve her problem but also causes repeated damage to her.

Because mental disorders are due to errors in psychological programs, psychotherapy should aim at learning the correct programs and modifying the inappropriate ones. Psychotherapists should also dig deeper into these psychological programs and aim to find ways to change them.

There is also a case that proves that improper use of psychological programs can create mental illness.(This case is from China's baidu tieba. The case is true, and it was the client's "psychological consultation bar" that made the public consultation, but it was anonymous.)

A woman with schizophrenia reported that she could always hear someone around her talking about her, but she could see no one when she investigated. She felt that her own auditory hallucinations were real. According to psychoanalysis, when she was in high school, she had poor interpersonal relationships and experienced great pressure in her studies. Once, she could not help but scream at her classmates during class, which made her even more isolated. Later, when the teacher came down from the podium and spoke to the other students, he whispered a few words about her. The therapist judged that this experience was not an auditory hallucination. The patient herself later admitted that she really did hear the teacher 
and her classmates talk about her.

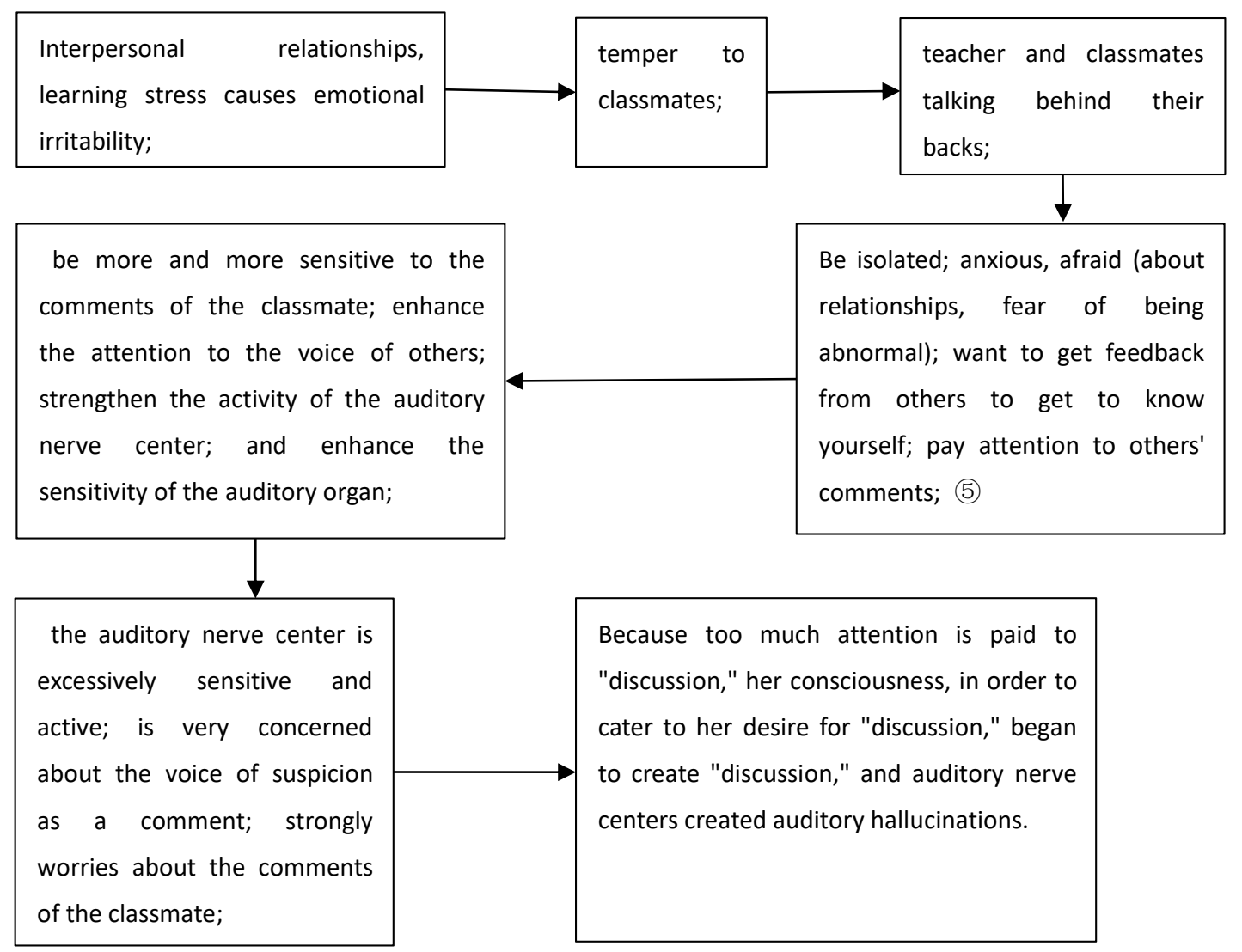

FIG.8

Later, because of her poor interpersonal relationships, she was sometimes discussed by her classmates behind her back. As a result, she became increasingly sensitive. As long as two students bowed their heads to talk, she thought they were talking about her. One day, when she was alone at home, she suddenly heard someone talking about her in a corner with a clear voice. She was shocked at the time because she knew that there was no one was there, and her auditory hallucinations came into being.

In this case, (E), you can see that her hallucinations are purely her own creation, that people's minds and bodies are closely related, and that she has repeatedly hinted at herself: others are talking about themselves, and when they do so much more, From quantitative to qualitative change, her brain was influenced by her own mental cues, which really produced the hearing of "others talk".

Others are like mirrors. We need feedback from others to understand ourselves and adjust our behavior. This girl has a bad personality and bad interpersonal relationship. She also needs feedback from others to know herself. When she loses her temper, she has a bad assessment of her own state, and she has the perception that "abnormal, other people dislike her". At this time, When others talked about her (she was really talking about her at first), she felt more worried and frightened. The more worried she was, the more sensitive she was to the comments of her classmates. Such constant self-suggestion made her finally appear to have the symptoms of hearing hallucinations.

Because of their different personalities (this is a different program of personality 
psychology), everyone has different responses to information from others, and even someone with a special personality doesn't care what other people think, but most people still pay attention to others talking about themselves. Some people care more about what others say.

The girl in the case has some worries about her interpersonal relationship and mental state because of her bad interpersonal relationship, great pressure of study, nervous and irritable mood, so she is more sensitive to the discussion of her classmates. "concern of others" is a psychological program, healthy people will not run this program too much, not too hard to run, not every moment to run the program, can not pay too much attention to other people's comments. And her problem is the wrong run of "pay attention to others talk" the psychological program, because she did not properly run the "pay attention to others talk about themselves" program, she created a hallucination of the symptoms of their own.(fig.8)

That is, due to the improper operation of the "attention to other people's discussion" program, there is a morbid physiological response such as "auditory illusion".

Therefore, a focus of treatment is the "focus on other people's discussion" program, which she needs to "brake, slow down." That is, she is too concerned about what others say, she needs to pay less attention to the intensity of other people's discussion. This requires willpower to control physical responses and restrain the urge to pay attention to what others are saying. This is psychologcial program modification, and in the program block diagram 8 , she needs to start with the program (5), and reduce the running of the program after (5).

At the same time, it is not enough to reduce the focus on "discussion". She is strongly concerned about "discussion" because of her own bad behavior, such as bad mood, angry with her classmates, etc. Therefore, she needs to deal with life stress and improve her personality and interpersonal relationships, which is the process of changing her "life and character" so as to eliminate the root causes of illness.

\subsubsection{THE CAUSE OF MENTAL ILLNESS IS GENERALLY DUE TO THE IMPROPER MANIPULATION OF CONSCIOUSNESS TO PHYSIOLOGY}

The definition of psychological program is to manipulate the action combination of physiology. If the individual consciously or unconsciously manipulates his own physiology is morbid, then this kind of "manipulation" is the cause of the disease.

In fact, all non-organic psychosis and psychological disorders are problematic with this "manipulation".

In the previous example $\mathrm{K}$, a person was watching $\mathrm{TV}$ and then decided to take to the street. in the conversion of these two tasks, he needed to turn off the physical and mental response mode of "watching TV." if he was shutting down the program, there was something wrong with the "manipulation" of physiology, and he wanted to close the physiological reaction of "staring at TV, immersed in the thrilling imagination of horror movies," and did not want to turn it off, when he repeatedly tangled with contradictions. Physiological reactions may be deranged, and psychological disorders may occur.Of course, this usually doesn't happen, and most people don't even believe it's going to happen. They think it's very simple. They don't even realize what's going on in the middle. They take it for granted.

In case $\mathrm{C}$ of forced thinking, it is also the physiological reactions such as "manipulation" of physiology due to thinking, "empty brain", "fox odour under left armpit", "numbness of left body" and other physiological reactions, such as "empty brain", "fox odour under left armpit" 
and "numbness of left body".

When individuals perform certain tasks, there will be many physiological manipulation that is difficult to describe in language, and the most common problem is "start, turn off". In the case of depression, there is " 1 " to activate energy supply, "0" about closed energy supply, where energy refers to "blood, oxygen, hormones, proteins, sugar" and other substances that supply physiological activities. When individuals decide to carry out certain tasks, such as "thinking", "eating", "imagination", "memory", "experience", "happiness", "excitement", "running", "talking" and so on, there is the behavior of "manipulation physiology" when carrying out these tasks, such as "closing" and "starting" all the time. Once these subtle manipulation is wrong, the "manipulation" is inappropriate. It can lead to a morbid physiological response.

That is to say, "operating system program" is easy to make mistakes, it is more error-prone than a certain innate physiological response (such as gastric acid secretion), and because "operating system program" is responsible for "turning off, starting" a task, it runs all over the body, is not limited to a specific organ, its physiological response is subtle and difficult to describe in language, so it is difficult to grasp, psychological counseling, Pay attention to the patient's description of some strange physical feelings, because these symptoms lead to her psychological symptoms.

\section{THE SEARCH FOR AND DETECTION OF PSYCHOLOGICAL PROGRAMS 8.1 HOW TO SEARCH FOR PSYCHOLOGICAL PROGRAMS 8.1.2 DEFINITION OF PSYCHOANALYSIS}

The psychoanalysis mentioned in this paper is different from Freud's psychoanalysis. The theoretical basis of Freud's psychoanalysis is based only on his own analytical theories, such as the theory of sexual psychological developmental stages and that neuropathy is the suppression of sexual instinct.

Freud's theory of sexual psychological developmental stage is only one of the many theories on psychological operations, which may not be correct. The theoretical basis of psychoanalysis is any theory about the principle of human psychology, such as Maslow's motivation theory, Adler's theory about inferiority, compensation, and birth order, Jung's personal attitude type theory, field dependence theory, and the defense mechanism of psychoanalysis, and lastly the theory of Horney and Fromm. Of course, these theories must be ones that correctly describe the principles of human psychological activity.

Psychological analysis refers to the exploration and search for the causes and processes of the individual's psychological activities, finding the source of a certain psychological activity of an individual and its specific process. For example, take the cause, occurrence, and specific processes of operation of the "forced anger" of the client in Case A. For the purpose of psychoanalysis, therapists can use various theories, including psychoanalysis, provided that the theory can correctly explain the laws and principles of psychological activities, and even the therapist himself can develop a theory, such as the "vacuum filling" principle proposed by the therapist in Case B.

\subsubsection{TECHNIQUES OF PSYCHOANALYSIS}

The purpose of psychoanalysis is to excavate the psychological procedure, find out the process of the patient's psychological activity, and clear up the background of the 
psychological activity. This can be analogous to the detective work of solving a crime. Detectives get the information they need through cross-examination, observation, and so on, to understand the crime process and restore the scene. The same is true of psychotherapists, who need a variety of psychoanalytic techniques, such as psychological tests, housekeepers, sand tables, conversations, handwriting, notes, free association, interpretation of dreams, observation of patients by relatives and friends, and even clothing of patients. Room layout and so on. In a word, all kinds of methods which can understand the psychological world of the patient and master the process of psychological activity of the other person can be used flexibly.

Psychological analysis itself does not cure mental illness. Its purpose is actually to find a psychological program. As mentioned above, because some psychological problems are simple, the program errors are not complicated, and people often instinctively know that some programs are wrong. Therefore, having undergone psychoanalysis and becoming aware of these programs, a patient may instinctively and immediately make modifications, which causes the psychoanalysis itself to appear to have healing power. However, most of the time, the reason why a patient has a mental and psychological disorder is precisely because he does not know what is wrong with his program or understand which program is wrong. This requires psychological analysis.

\subsubsection{SCIENTIFIC HYPNOSIS}

For most mental and psychological illnesses, psychoanalysis alone cannot find psychological programs, and it is difficult for patients to perceive the etiological programs themselves. For example, in post-traumatic stress disorder, the psychological program goes wrong in an instant, and it is accompanied by strong, painful emotions. It is difficult to analyze these programs in psychoanalysis under normal conditions. William S. Kroger once said that hypnosis is a state of increasing awareness. ${ }^{[1]}$ To isolate the psychological program of a patient with psychological impairment, it is best to use hypnosis to awaken his memory and increase his awareness. Its significance can be likened to surgery performed by surgeons.

From the above cases, it can be seen that the method taught by the therapist was difficult for the clients to learn. This is because the clients are not familiar with the psychological programs that caused their own troubles. This requires hypnosis to dig deep and analyze these programs so that the clients can grasp them.

Judging from the known clinical hypnosis work, hypnosis can uncover memories very well. It is difficult for patients with psychological disorders to recall specific feelings in their psychological symptoms under normal conditions, and only when the patients can sufficiently recall delicate details in specific psychological disorders and activities can they change. In fact, the work experience of many hypnotists shows that although hypnosis does not really cure patients, it does reduce the problem to a certain extent in a short period of time. This is actually what was said above: once the patient recalls his psychological activities at the time, he/she may instinctively understand how to adjust himself/herself. This is because some minor programs have gone wrong, and even without professional psychotherapy training, he/she can know appropriate from inappropriate functioning based on his/her life experiences and common sense. The key is that he/she cannot remember the activities!

Therefore, hypnosis is a powerful tool. The situation of immediate improvement after 
recalling the situation at the time was misunderstood as a merit of hypnosis or psychoanalysis itself, but such improvement was actually due to the patient's own modification of the program. However, because it happens so quickly, it is difficult for others to notice the process. Hypnosis itself cannot be used as a therapy independently, but it can play an extremely important role in digging deep into the psyche and isolating the program in the complete treatment process of "psychoanalysis + modification of psychological programs."

With hypnosis, the patient can ultimately be aware of and familiar with the programs, and the therapist then helps him/her modify and adjust these programs.

As Erickson wrote in his book Hypnotherapy: An Exploratory Casebook, "We believe that the induction and maintenance of therapeutic hypnosis provides a special state of mind where patients can reconnect and reorganize their inner experiences. The curative effect will be generated from the resynthesis of self-reaction." [2] This statement not only indicates the existence of psychological programs but also suggests that hypnosis can act on and modify them. The "reconnecting" and "reorganizing" mentioned are the reconnecting and reorganization of psychological programs.

\subsection{PHYSIOLOGICAL MEASUREMENT OF PSYCHOLOGICAL PROGRAMS}

Because psychological program is the combination of psychological activity, every living person has psychological activity, even every living organism has psychological activity. There is psychological activity, of course, there is psychological program, therefore, the existence of psychological program is self-evident, it is only an abstract description of psychological activity, it is only an abstract concept. It doesn't need proof, but it can be measured.

Psychological programs require a large amount of time and space to run. The physiological changes, when they run, are hidden from view, and many of the psychological programs are related to the external environment as well. Some psychological programs occur between individuals or between individuals and other externalities. Therefore, psychological programs are difficult to present in the laboratory setting and are quite difficult to study with empirical research as well. However, experimental evidence is still achievable.

Some programs can be artificially stimulated and measured in the laboratory, whereas some are more suitable for measurement in the natural environment. This requires special instruments that can be carried or installed in the body of the test object unobtrusively, which can measure the physiological indicators of the physiological responses evoked by the operation of these psychological programs without affecting the person's life.

The operation of the psychological program will initiate a series of physiological reactions. Therefore, changes in physiological responses are the manifestations of the programs. Therefore, although the programs are abstract and invisible, they manifest through changes in physiological responses. Therefore, the existence of such a program can be confirmed by systematic and global measurement of dynamic and static data of physiological indicators of the human body.

From the definition of psychological program, physiological changes or physiological responses are the manifestations of psychological programs. Therefore, to measure a psychological program is to measure its physiological changes or physiological responses. To be precise, it is to measure the combination of physiological changes or combination of 
physiological responses because the same physiological changes may belong to different psychological programs, and it is only meaningful to measure their combination.

Because psychological programs can run throughout the body and are a combination of physiological changes, measurements should be taken from both the spatial and temporal dimensions.

Spatial measurement refers to stereoscopically and holistically measuring the physiological changes of an individual's entire body that may belong to the program, including different organs, internal tissues as well as the external surface, blood flow, and bioelectricity.

Temporal measurement measures the time sequence of various physiological changes, the time of each physiological change, time intervals, and the like.

Not only should we measure from the two dimensions of time and space, we should also measure other variables, such as the intensity of a single physiological change.

Only stereoscopic measurements from the integral and dynamic perspectives can confirm the existence of these programs, and in deceased individuals, these programs cannot be measured.

The operation of psychological programs is inseparable from the body, and its control over the physiological responses is dynamic and holistic. For example, in the compulsive thinking case, the act of thinking involves the entire body. Namely, the subject reported that when he was thinking hard, the muscles in the back of the neck were stretched tight like a bow, and he was even more afraid of the cold than usual (which indicates that blood flow to the skin was reduced). Dynamic characteristics mean that these physiological responses change accordingly with changes in a program's operation. For example, when he was thinking compulsively, he felt colder than usual, but if he was not thinking as hard, he would not feel so cold, indicating that the blood flow to his skin had changed. This shows that when people run this thinking program, the blood flow to other body parts, including the skin, hands, feet, and the digestive system, decreases, while the blood flowing to the brain increases. These physiological changes are all easy to measure.

\section{ALTERATION OF PSYCHOLOGICAL PROGRAMS}

\subsection{PSYCHOLOGICAL PROGRAMS CAN BE ALTERED}

Because "running psychological program" is "implicit behavior", therefore, modifying psychological program is to change implicit behavior. "implicit behavior" can be changed, and people are the same precisely because their psychological programs are different, so if one person can artificially change the program of his own psychological activities into that of another person, Then he has psychological characteristics similar to that of that person. Implicit behavior is not inherently fixed and immutable. In fact, a lot of "implicit behavior" is established the day after tomorrow and can be changed.

A person's psychological disorder is precisely because of his morbid implicit behavior, which can be treated by consciously changing his implicit behavior. This kind of "implicit behavior" modification, that is, the modification of psychological program, is similar to the change of computer program.

The second half of psychological treatment is the alteration of psychological programs. The purpose of the first half of psychoanalysis is to find the pathological program and then 
alter or eliminate the erroneous program in order to cure the disorder. In comparison to psychoanalysis, the alteration of the psychological program is much more difficult.

Psychological programs can indeed be altered with conscious effort. Psychological programs constitute a series of actions in our mind and body. Our consciousness can exert conscious and limited control over our body and physiology (this is determined by the nature of life itself; life is intelligent, has free will and the ability for subjective initiatives. Such subjective initiatives not only refer to the ability to control the external environment, such as lifting a glass but also the ability to control and regulate our own physiological activities). We can consciously choose to initiate or not to initiate certain physiological activities, which in turn alters our psychological programming. Similar to how computers can be programmed, human beings can also program themselves in certain ways.

Subjective consciousness can regulate and influence physiological activities: this is the foundation of the alterability of psychological programs. For instance, when we are upset with someone and about to lose our temper, we can relax our nerves and ease the urge to lash out by taking deep breaths. This action entails conscious control of our physiological activities, although such a method of control may not always be the most appropriate. As another example, in the middle of class, a student who suddenly feels a strong urge to urinate but chooses to wait for the class to end also exerts conscious control over the physiological aspects of the body. Therefore, when consciousness influences and alters the physiological activities of psychological programs, it can alter such psychological programming.

Many existing psychological treatments work by changing and affecting psychological programs. For example, cognitive behavioral treatment focuses on changing the sources of the program, such as beliefs and values.

Biofeedback therapy works by consciously controlling physiological feedback, which is also a way of altering psychological programming.

The principle of humanistic therapy is to encourage patients to utilize their own psychological programs, because in many patients, their disorder stems from the inability of their psychological programs to adapt to life and society. Adopting a patient-centered approach, humanistic therapy enables patients, with the guidance of therapists, to use the psychological programs that they are usually unable to use under other circumstances, consequently relieving their pain. Moreover, by allowing the original psychological program to operate freely and securely, humanistic therapy allows the patients to become aware of the inappropriateness of particular psychological programming. Similar to Freud's free association or hypnosis and consciousness, the free and relaxed operation of humanistic therapy allows the client to gain awareness and recall the operational errors in their psychological programs, thereby achieving a therapeutic effect.

Behavioral therapy controls and changes one of the forms of expression of psychological programming, namely, explicit behavior.

Even psychotropic drugs are designed to directly control and influence the end result of psychological program operation, i.e., physiological response and physical action.

7.2 The Rules of Altering Psychological Programs

\subsubsection{Seamless access to programs}

In the alteration of certain pathological programming, the implantation of a new program is best performed as a natural continuation at a specific segment of the original, healthy 
program. In this approach, the newly implanted programming needs to follow the "spontaneous and natural" operational rule; otherwise, in later stages of life, it will be difficult for the newly implanted programming to operate spontaneously.

\subsubsection{Compatibility of psychological programs}

Similar to computer programs, there are also compatibility issues in psychological programs. For instance, consider an individual who suffers from a phobia (Case Study D) and feels extremely nervous whenever he sees a ballpoint pen. In this instance, solely using a deep breathing technique will not truly solve the problem. Instead, we need to analyze the reason for the patient's anxiety and nervousness. As it turns out, a few years ago, he was a stay-at-home parent, and his daughter fell down while playing with a ballpoint pen. The pen pierced through her neck, and the injury was almost fatal. His wife blamed him for the incident, and he regretted allowing his daughter to play with the pen. Since then, he has developed a subconscious fear that manifests whenever he sees a ballpoint pen.

In this case, we need to identify the changes in his psychological programming that occurred when he was traumatized by the scene of the ballpoint pen piercing his daughter's neck. Alteration can be performed once the error in his operating psychological program is identified. This process is distinct from directly using irrelevant programs (relaxation, deep breathing) that are unrelated to the original program's system to control the body's physiological reactions (although this may provide temporarily relief in emergency situations, it will not solve the underlying problem) because such an approach cannot be automated, i.e., we cannot expect the patient to start relaxing and taking deep breaths every time he sees a ballpoint pen.

This characteristic of psychological programs is very similar to organ transplantation. If the transplanted organ has high genetic similarity to the recipient of the transplantation, the chance for survival is much higher; otherwise, there is a high likelihood of rejection.

\subsubsection{Allowing the program to operate in its entirety}

Once an abnormal segment of psychological programming is implanted, in order to eliminate this segment, it must be hampered at its origin. We cannot wait until it begins to operate and attempt to repress its operation with pure willpower ("antagonistic" reactions often result from such process). Once it begins to operate, we can try to stifle its strength, for example, through limited deep breathing, conscious relaxation, limited attention shifting, etc. However, as described previously in the "program compatibility" rule, such "deep breathing" and "relaxation" techniques have limited effectiveness, and the removal of dysfunctional programs cannot solely rely on such processes.

9.3 Methods to establish or alter psychological programs

Psychological programs are altered through conscious control of physiology. For instance, in Case Study A, the participant's abnormal anger programming was created by her conscious control over her physiological activities (she restrained herself from outbursts towards others and confined herself to experiencing pure "anger"). In other words, she artificially altered the normal physiology of anger into her own expression of anger; such artificial change is inseparable from her subjective will. The difference between "normal anger" and "abnormal anger" is the difference in physiological activities.

The psychological programs of a living being are partly hereditary, while others, such as the psychological programs of personality, are created at later stages of life. In fact, we are 
constantly eliminating or altering old psychological programs and establishing new ones. The establishment of psychological programs materializes as our "consciousness" exerts control over our physical and physiological responses. Such "consciousness" can be further divided into "conscious" and "unconscious" elements; for instance, personality programs are often gradually shaped through our interactions with others, by either active or passive consciousness.

While many parts of "personality programs" are created consciously, as time passes, the individual will forget these creation processes. In contrast, in the unconscious creation of the programs, the individual is not even aware of how these programs are created, let alone how they may be altered. Therefore, in psychotherapy, methods such as psychoanalysis and hypnosis are required to uncover memories and allow these programs to surface such that the individual can become consciously aware of them and perform the necessary alterations.

In the traditional treatment of mental disorders, physicians often only focus on changing the patient query responses. However, while such a treatment method may convince some physicians that the treatment administered has been effective, there is no actual benefit to the patient at all. In contrast, patients must display behaviors that are inconsistent with their true selves in order to act in concert with the physician, which may lead to further suffering.

Since psychological disorders are caused by erroneous programs, the purpose of psychological treatment should be the abandonment of old dysfunctional programs and the establishment of new psychological programs, or the alteration of the original pathological program.

\subsubsection{Retrospective analysis}

Using psychoanalysis and the hypnosis method, we can attempt to identify at which point the program becomes distorted or how abnormal programs are implanted. Once the issue is identified, the patient is guided to return to the original program or the original state and to re-establish operation according to the direction of the original program or to inhibit the activation of abnormal programs, abandoning the erroneous path or abnormal program.

For instance, in the previously illustrated Case (A) with a female patient who suffers from compulsive anger, when the therapist asked her to recall why she became angry, it was discovered that her mother used to abuse her verbally and physically. The patient should have followed her anger impulse and become furious with her mother for this abuse, as this would have been the correct program. However, sometimes, our operating program becomes erroneous when we forget how exactly it should operate. Physiological reactions, including brain activities, that cause the operation of psychological programs may be very limited. However, although these physiological activities and responses are minimal (so minimal that we often are unaware of and question their existence), they are still crucial, and neglecting certain processes can lead to psychological dysfunction.

From the perspective of a healthy individual, it is unthinkable that we could forget how certain programs should operate. For example, in the case of the patient with anorexia, she may forget how to eat. Such forgetfulness does not mean that she has forgotten how to pick up a spoon or use a fork but that she has forgotten the sensation of appetite, the desire to eat and how to respond when she feels hunger.

In reality, the exact mechanism of the operation of psychological programs can be easily forgotten. Under normal circumstances, when a program runs uninterrupted, the program is 
likely to run smoothly and error-free, but once it is interrupted by external factors or excessive fluctuation in individual emotion (when the emotion evoked is too intense, the individual will be lost in the process and forget that the program has not been completed, subsequently forgetting how it should be completed), we may forget some parts of the program and how it should operate.

The male patient who witnessed a ballpoint pen piercing his daughter's neck will also encounter other anxiety-provoking situations in his life, but he knows instinctively how to handle them, so when he faces an anxiety-provoking situation that he can handle, the anxiety will fade away once the problem is solved (able to complete operation and knows how to operate). However, the ballpoint pen incident interrupted his anxiety response program, and immediately after the incident, he had to handle his daughter's injury (calling the doctor, notifying his wife, etc.), which led him to forget the preexisting anxiety response program. In other words, he forgot how to extinguish the feeling of anxiety (every time we successfully handle a stressful event, we can restore our emotion to its original state; such emotional recovery is also a part of psychological program). Since the incident, he has likely felt trapped in his feeling of anxiety and has not known how to diminish it. Therefore, in such circumstances, hypnosis can be used to help him to recall how anxiety can be diminished; in other words, hypnosis can help him to remember how his "anxiety-diminishing" program works. In fact, such a concrete way of operating psychological programs is often not understood by most therapists. Even if therapists are aware of such a technique, they cannot directly teach the patients how to "diminish anxiety." The best way to accomplish this sort of goal is to let the patient use his intuition and experience his own memories.

There is another circumstance in which individuals may forget how certain programs should operate, namely, under the interference of our consciousness. When a certain program starts to cause dysfunction, or sometimes out of pure curiosity, we may consciously try to examine and analyze the program. Consequently, instead of achieving clarity, we become more confused and unable to recall how we operate the program. Under such circumstances, it is best to take a rest and use our intuition and memory to recall the original experience.

\subsubsection{Use and disuse}

"In the evolution process, some organs of the organism will degenerate by either shrinking, simplifying, becoming less functional or non-functional." If any human organs, such as our hands, have not been used for a long time, after N-number of generations pass, such organs will eventually degenerate and even vanish. The same thing can happen to psychological programs: once a program's usage is gradually reduced in daily life, its potency will also gradually decline, and eventually it will slowly vanish, in line with the use and disuse principle. This method can be used when we want to eliminate or weaken a harmful psychological program, such as the previously illustrated compulsive anger program. The key to this method is to not use the program. Such a technique does not mean that we forcefully stop the program's usage but that we gradually decrease the frequency of its usage. Development occurs in a wave pattern, where progression and regression take turns occurring. The same applies to the elimination of these programs: we can allow the program to recur naturally, but its overall frequency of occurrence and potency are reduced.

Based on behavioral theories, in the disuse process, rein 


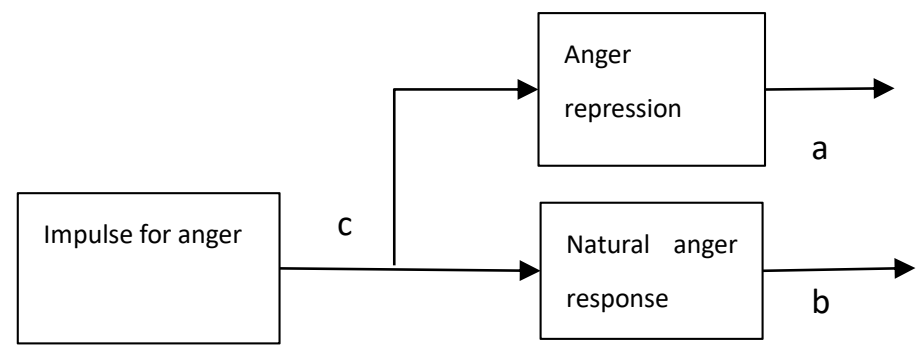

Fig.9

forced behavior may reemerge after being inactive during the disuse period. Psychological programs face similar complexity in the disuse process, and such complexity should be seen as a natural part of the process.

\subsubsection{Reinforcement of preexisting programs.}

In Case Study A illustrated above, the program shown in Chart 2 is the anger program of a healthy individual. "Feeling angry when tormented by others or even attacking the tormenter" is a natural instinct, and hence, the psychological program shown in Chart 2 is the closest to an individual's innate program. On the other hand, Chart 1 shows the distorted program created by the patient. As the Chart 2 program existed in the patient prior to the formation of the distorted Chart 1 program, it is termed the "preexisting program."

The problem began when the patient distorted her psychological program for "anger repression", as shown in Figure 9.

Point c, "anger suppression", was the point at which her psychological program began to digress from normality. In the figure, at point $\mathrm{c}$, the program moves forward in two different directions, $a$ and $b$. To encourage the program to continue operating along direction $b$, in addition to the "use and disuse" approach to minimize the program operating in direction a, a natural approach should also be used by allowing her psychological program to progress along direction $\mathrm{b}$ before reaching point $\mathrm{c}$.

As the preexisting program was established first, it has existed longer than the digressing program (the program that begins from point $\mathrm{c}$ ). The program digresses at point $\mathrm{c}$; nevertheless, there is a certain inertia for the preexisting program before it reaches the point of digression. In the operation of any psychological program, there is always the tendency for inertia to maintain its course of operation. Therefore, by making use of the inertia of the "preexisting program" before it reaches the digression point, an individual can avoid progression towards direction a and operates along the normal direction (direction $b$ ).

When the patient reflects on her mental activities, she will find the anger impulse prior to the digression point (prior to anger repression). This anger impulse operates along direction $b$, such that when she is tormented, her original reaction is to become angry, she will still have the impulse to be angry at another person, and there is inertia in her anger impulse. When she finds this impulse, she should not repress it; instead, she needs to allow it to progress naturally as per her inertia. In doing so, she can allow her "preexisting program" to operate along its own direction, $b$. 
Therefore, the "preexisting program" remains usable, and as it has existed for much longer than the digressing program and is indeed the foundation of the digressing program, it has existed prior to the point where program digresses such that there is a certain inertia in it. For this reason, we call this phenomenon the "reinforcement of the preexisting program".

\subsubsection{Expansion of sensation}

First, we will define the concept of the program boundary (sensation boundary).

Here, the shape and borders of sensation resulting from a psychological program's physical and physiological influence is defined as the sensation boundary or program boundary. For the aforementioned patient with the compulsive anger problem, the anger program leads to the tensing of the right side of her body. This tensing sensation can be clearly felt by the patient herself. In her subjective experience, once tensed, the right side of her body feels like it has turned into a separate entity, and this entity has a shape and borders. Such shape and borders are the boundary of sensation.

When the patient feels this shape and border, she can separate them from other physical sensations (in order words, she can distinguish between the pathological program and other programs). She can then apply the use and disuse technique to handle this sensation (as this sensation is also a part of the psychological program). This technique is similar to a surgical procedure in which the surgeon needs to identify the edges of the tumor that must be removed prior to the surgery; otherwise, it will be difficult for the surgeon to determine the exact incision site.

By expanding our sensations, we can identify the boundaries of physiological sensation caused by psychological programs. Only by not limiting our exploration of physiological sensations caused by specific programs, instead expanding that exploration to a wider zone, can we then identify the boundaries caused by such programs. As the saying goes, "you cannot see the forest for the trees". If the individual exits the forest or examines his surrounding from a helicopter, he will notice the true shape of the forest. Thus, individuals need to expand their sensations.

The objectives of sensation expansion are to allow us to escape the program that controls us, identify the basis of the pathological program and see the pathological program as a part of a bigger parent program. In this way, we can identify the source of the program, understand the reason behind its formation and where it begins, and, subsequently, become able to abandon it or make necessary alterations.

\subsubsection{Referencing method}

One example of a type of psychological program is self-confidence. Consider, for example, a client who is not confident in some aspects of himself, such as feeling inferior due to his poor drawing skill. He needs to develop more confidence in drawing. To accomplish this, first, he needs to identify other aspects of himself that he is proud of, and generally, this is an achievable task. Suppose he is very confident in his ability to ride a bicycle. The psychological programs for confidence in bicycle riding and drawing are the same. If the therapist helps the client analyze his confidence program in bicycle riding, he can be taught to apply the same confidence to his drawing. As he already possesses the confidence program for bicycle riding, it will be easier for him to learn the utilization of the self-confidence program in other areas.

9.3.6 Third-party intervention in psychological procedures. 
All of the above modification methods depend on the patient's own subjective efforts, and the patient modifies by manipulating his own physiological activities. However, for severe mental patients, communication is difficult and learning how to modify psychological procedures. Here's a possible way to modify it by someone outside.

Tiny machines can be placed on the patient's body, placed in the various physiological organs in which the psychological program runs, and these machines can even be moved. The machine can be placed in the brain tissue, near the neurons that run a psychological program, in the spine, around the nerve that the program runs, and in the organ in which the psychological program produces a physiological response, such as the adrenal gland, etc.

These machines connect nerves and physiological organs, and interfere with the operation of psychological programs by releasing electrical pulses, changing and affecting the signals of nerve pulses and bioelectricity released by patients when they run psychological programs. These machines also carry chemical and biological drugs, releasing chemical transmitters, hormones, etc. at the right point and place to alter the physiological response of the psychological program, thus affecting and interfering with the operation of the psychological program.

Of course, this is only theoretical, and it is difficult to do so in practice. We need to calculate exactly the physiological response, calculate the amount, time and position of the physiological response, and then, at the exact time and position, the machine releases electrical pulses and biochemical drugs.

10 Quantification of Psychological Phenomena and Scientification of Psychology

10.1.0 Quantification of psychological programs and psychology

Indicators for emotional measurement primarily comprise subjective experiences as the internal indicators, while external indicators usually include behaviors and physiological changes in the body, etc. ${ }^{[3]}$

We believe that all psychological phenomena can be quantified using the "bodily physiological changes" that have been used as emotional measurement indicators. Only by using such indicators can quantification become scientific.

However, there remain many issues with "physiological indicators of emotion," including that there is no one-to-one relationship between an emotion and a specific physiological indicator. ${ }^{[4]}$ The same physiological indicator, such as adrenaline excretion, can be caused by "rage" or "fear," even though "rage" and "fear" are two distinct psychological programs. Therefore, simply using a physiological indicator to quantify certain psychological phenomenon (e.g., rage) makes it less likely that we will find the corresponding physiological indicator data for each program. The measurement of adrenaline excretion we obtain in order to quantify "rage" may also contain the adrenalin excretion resulted from "fear." Multiple psychological programs operate within an individual at any given time, and the data for physiological (including brain) changes is vast and messy; therefore, it is inadequate to quantify psychological phenomena solely based on these indicators.

Therefore, the quantification of psychological phenomena must be based on psychological programs. Only by identifying the psychological program of the psychological phenomenon can we identify the corresponding physiological reactions (changes), thereby quantifying psychology in a concise manner.

In Rust and Golombok's "Modern Psychometrics", they wrote, "for instance, unlike 
physics or chemistry, we don't even have consensus on what is the basic measurement unit of psychology. Traditionally, behavioral measurement (in particular stimulation and response) was favored, but later on, "information" has also come into play."[5]

This paper believes that psychological phenomenon is realized by running psychological program. Since the psychological procedure corresponds to the physiological response or physiological change, and the physiological response or physiological change has physiological index as the data, so the quantification of psychological phenomenon shall be made with the physiological response as the quantification object, and the indicator of physiological response is the basic unit of psychology.

There is a corresponding physiological reaction to any psychological phenomenon; therefore, quantification is possible for all phenomena. Every item in psychology, such as charm, talent, personality and emotion can be quantified. However, the quantification of psychology needs to allow for the ambiguity of "consciousness" because such ambiguity means that absolute quantification will not be possible.

We propose a law of psychology: all psychological phenomena have a physiological basis, and there is a corresponding physiological change to any psychological phenomenon.

The direction for quantification should be the quantification of psychological programs. The quantification of psychological programs refers to the quantification of the physiological changes of the psychological program.

10.1.1 Scientification of psychology and psychological experiments

Current psychological experiments use data that are subjective and indirect. For example, the direct quantity measurement method is a type of direct measurement but also relies on the individual's subjective estimates, whereas the constant stimulation method and the minimal change method are indirect measurement methods. These data do not meet the stringent scientific requirements of experiments.

For psychology to become a real, empirical "science of the mind", we need to directly measure the physiological reactions of psychological phenomena. As psychological reactions generate a vast range of data, we must rely on the analysis of psychological programs to isolate the psychological reactions of the psychological phenomenon under study from background noise. In other words, we need to analyze the psychological programs of psychological phenomena, followed by measuring the physiological reaction indicators of these psychological programs, thereby attaining direct, scientific and empirical data for these psychological phenomena.

We can also use physiological reaction measurement to accomplish reverse deduction of the subject's psychological activities. In this way, similar to physics and chemistry experiments, we can perform objective measurement of the individual activities and obtain empirical data from the experiment.

In fact, psychological experiments are difficult to repeat, probably because the repeated "object" is wrong, that is, the "psychological effect" should not be repeated. The psychological phenomenon of human being is changeable, the psychological effect is greatly influenced by the human being and the environment, and even changes with evolution. At different historical stages of human being, the expression of a psychological effect is different, so it is very difficult to repeat it.

But if we replace the repetitive objects of psychological experiments with 
"psychological programs," we can use psychological programs to describe psychological phenomena that are closer to nature. Although psychological programs are a combination of physical responses and abstract, it is precisely because they can express the essence more. In order to ignore the psychological effects of uncertainty. Finding similar psychological program structures among different individuals is more reliable and stable than repeated psychological effects.

\section{APPLICATIONS OF THE "PROGRAM" MODEL TO OTHER DISCIPLINES}

\section{1 GENERALITY OF MODEL}

A program is a universal model that describes both the physical world and human society.

Sunrise and sunset, planets orbiting the sun, air rising in heat, apples falling to the ground, these are all the running programs of the universe and nature.

In macroscopic physics, for example, when the earth moves around the sun, the relationship between quantity, mass, distance and gravity is fixed, so it can be described by mathematical equations. But in the field of organic life, the relationship between quantities is variable and cannot be uniformly described by a fixed equation (but can be described separately). For example, the psychological phenomenon of "fear" has physiological variables such as "adrenal secretion, dilated pupils, sweating". The relationship between these quantities is not fixed, and the "quantitative relationship" will change.

A trainer first saw the tiger would be afraid of, at that time, his physiologic variables of the "fear", there is a relationship between but he after many times of contact with tiger, he will slowly to control their psychological, at this time, "fear" physiological variables change, no longer so much he adrenal secretion pupil is no longer so big, and the relationship between these variables are no longer saw the tiger for the first time, the relationship between the changed the relationship between "variable".

If he built an equation for the relationship between the physical quantity of his "fear" when he first saw a tiger, it would fail after many encounters with the tiger because the "quantity relationship" changed. In this way, if he had to use equations to describe his psychological phenomenon of fear, he would have to constantly modify it. The first time he saw a tiger was an equation, the second time he saw a tiger was an equation, the third time, the fourth time, etc., which required many equations, and the mathematical equation model was cumbersome and unnecessary here.

And different people have different "fears" about the tiger, so the equation is different. The fear equation of the same person is different, and the fear equation of different people is different, which requires a lot of equations to describe, and the equations are not useful at all like the equations in physics.

\subsection{THE LAWS OR PROGRAMS OF THE LIVING AND PHYSICAL WORLDS HAVE THE SAME PROPERTIES}

The laws of the inorganic material world are not fixed laws, in fact, the laws of the material world and the laws of human society are laws of change. There are no "laws" in 
physics, and no "laws" in economics.

Here's an example:

Newton's law does not conform to the Galilean transformation, Galileo's relativity principle and transformation do not exist.

Newton's second law is not the same in two reference frames moving at relatively uniform speeds. For example, if you experiment with Newton's second law on a moving train, and you experiment with this law on the ground, the two Laws of Newton's second Law are not exactly the same mathematical form.

Because the gravitational force on a moving train is not the same as the gravitational force on a stationary object on the ground. (It should be noted, of course, that Newton's equation for gravitation is incomplete. It does not have a "velocity" parameter, which is included in the author's modified equation for gravity.)

That is to say, Newton's second law on a train is not in the same mathematical form as it is on the ground. The same was true of Galileo's experiments with large ships. Objects in a moving ship were subjected to different forces than those in a stationary one, but people in the hold of the ship did not notice.

Newton's law does not satisfy the principle of relativity, it is only approximately the same in two reference frames.

All laws of physics do not satisfy the principle of relativity. Any laws of physics are strictly different everywhere in the universe, and there will always be some difference in their mathematical form.

The laws of physics and psychology will change, just in different time spans.

The paper can be said that the laws of the physical world and human have the same property, are the laws of change, have the scope of application, the laws of physics are not necessarily universal in the whole universe. The laws of the material world and the living body have the same characteristics. The laws of human beings and human society are not more special than the laws of the material world. They can both be described by programs or mathematical equations.

In psychological phenomena, there is relative stability, which is the relationship between the physiological variables of a psychological program. This stability is a temporary stability, and the mathematical model can only describe this temporary stability. When the individual's physiological relationship to the program changes. For example, in Case A, when the quantitative relationship between the physiological quantities of anger is changed by treatment, the original mathematical formula is useless.

In fact, mathematical equations are physically the same and can only describe "locally stable phenomena,"

It's just that mathematical equations need to look for what we call "stable relationships between variables," and in the physical world they need to look for stable relationships between variables, and in human society as well. Both man and physics can be described by program and mathematics. Qualitative research is looking for "program", while quantitative research is looking for mathematical equations.

\section{3 IN THE HISTORY OF SCIENCE, THERE HAVE ALWAYS BEEN TWO WAYS OF DESCRIBING LAWS: MATHEMATICAL EQUATIONS AND PROGRAMS.}


The mathematical way everybody now knows that gravity uses equations, for example, the universal gravitation equation.

But the procedural way has been less noticed, but it's actually older and more common than the mathematical way. We know things and we use them all the time. For example, the qualitative description of "heavy objects falling" means a "program", which is a program in which nature operates.

"Old people will die," this is also said to be a program.

"Don't work hard or you'll be fired" is another program.

"Men like beautiful women" is another program.

When we perceive things and make so-called "theories" and "ideas", we are discovering "programs".

But mathematical equations have fatal limitations. They can only describe fixed relationships and cannot adapt to change.

For example, the universal gravitation equation formula is fixed, and the gravitational constant is also fixed. This is less of a problem in the natural sciences, but less so in psychology and social sciences. Because the quantitative relationships in the psychological and social sciences change, that is, the equations change.

In fact, the "fixed relationship" is only a local phenomenon, the universe as a whole is not fixed relationship. The laws of physics only apply to "uniform" and "local" parts of the universe, where "relationships between variables are stable regions." The invariable nature of the laws of physics is a special case; the laws of the whole universe are changeable 。

In the dimension of space, the equations of gravitation may not be the same everywhere in the universe, the constants may be different, even the whole equation may be different.

Similarly, in the dimension of time, the gravitation equation of 100 million years ago may not be the same as it is now.

"Laws" are inherently changeable. There is no "gravitation equation" that always applies. There are only laws of change: programs.

\section{4 PROGRAM IN ECONOMICS}

Economics begins by describing economic laws in terms of "programs," such as Quesnay's economic chart:

"He drew a lot of curves to represent the resources that flow around the economy. Farmers produced economic surpluses and paid rents to landowning nobles, who in turn bought silk buttons and silver candlesticks from artisans. The artisan in turn buys food from the farmer, thus completing a cycle. The economy is a residual circulatory flow between farmers, landlords and artisans. As surplus increases, more resources flow between them and the economy grows. When surplus shrinks, the economy shrinks, as the physiocrat sees France."

This passage is from Yale University's General Economics, in which the description of economic activity is the programs:

Farmers produce economic surplus $\rightarrow$ pay rent to nobles $\rightarrow$ nobles buy buttons and silver candlesticks from artisans $\rightarrow$ artisans buy food from farmers

This is the program economic activity. 


\subsection{PROGRAMS IN BIOLOGY}

DNA is what stores program instructions. The genes in DNA encode the instructions to make the proteins that carry out life's work.

Cells are like Cpus, where the computations (compilations) result in proteins (executables), and genes are the binary code.

So cells work by running programs, and organisms work by "running programs."

\section{5 THE RELATIONSHIP BETWEEN "PROGRAMS" AND COMPLEX SYSTEMS}

The program model can be used as a model to study complex systems, which is contrary to the idea of cellular automata. Cellular automata go from "part" to "whole", and "program" from "whole" to "part". The program model look at the system as a whole and analyze programs from it.

For example, Quesnay started from the whole economic system, the analysis of the economic activity programs namely the economic table.

\section{CONCLUSIONS}

The point of this paper is not to suggest that psychological program exist. Because psychological program already exists, it is the combination of psychological activity. The emphasis of this paper is to point out that the essence of non-organic psychosomatic disease is disorder of psychological program, which can be treated by modifying or replacing psychological program, and psychological program can be modified. The paper also holds that the psychological program can be used as the basis of quantification of psychological phenomena and as a general paradigm in various fields of psychology.

\section{References}

[1] Michael D. Yapko. Translated by Juan Gao. "Trancework: An Introduction to the Practice of Clinical Hypnosis" [M]. Beijing: China Light Industry Press, 2017.

[2] Milton H. Erickson, Ernest L. Rossi. Translated by Shou Yu. "Hypnotherapy: An Exploratory Casebook" [M]. Beijing: China Light Industry Press, 2016:6.

[3] Xiuyan Guo. "Experimental Psychology" [M]. Beijing: People's Education Press, 2004:573.

[4] Xiuyan Guo. "Experimental Psychology" [M]. Beijing: People's Education Press, 2004:584.

[5] John Rust, Susan Golombok. Translated by Siyao Li, Mou Jingjing. "Modern Psychometrics" [M]. Beijing: Renmin University of China Publishing House, 2011:22. 